بررسى تأثير فصل كاشت بر عملكرد و فنولوزى ارقام سيبزمينى (Solanum tuberosum L.) با استفاده از شاخص هاى نورى و حرارتى

عبدالستار دارابى 1 - ت

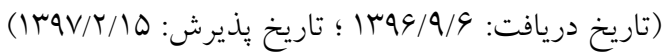

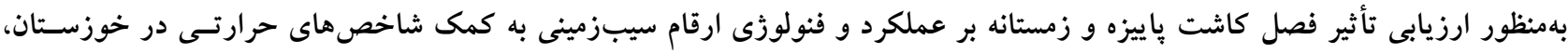

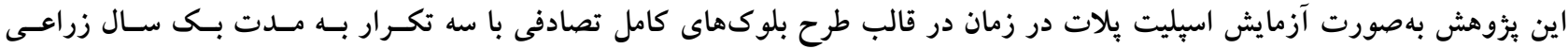

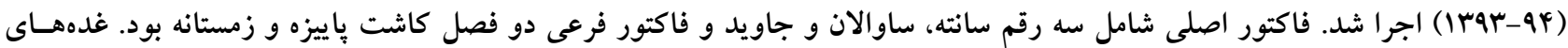

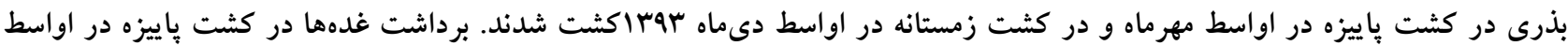

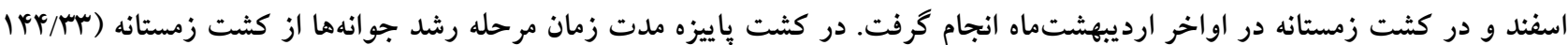

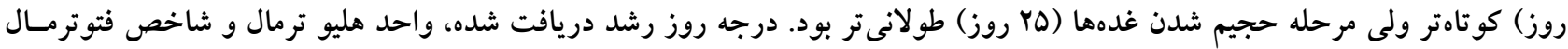

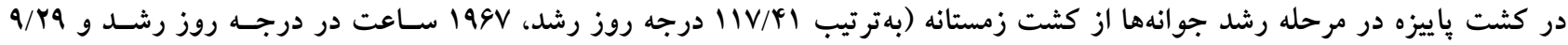

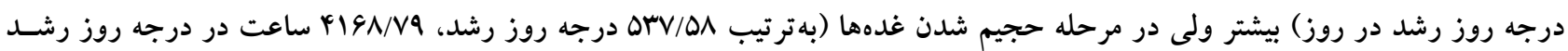

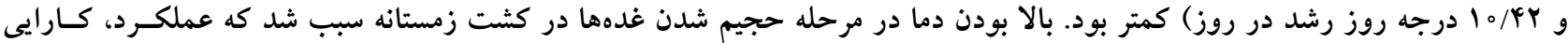

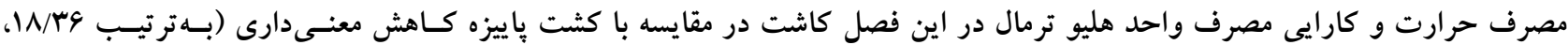

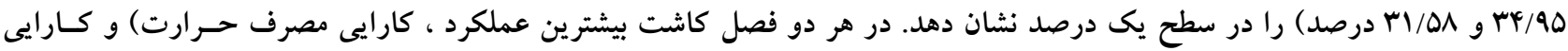

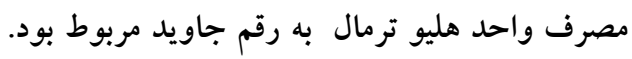

وازههاى كليدى: درجه روز رشد، واحد هليو ترمال، شاخص نورى دمايى، غدهزايى

ا. استاديار بخش تحقيقات اصلاح و تهيه نهال و بذر، مركز تحقيقات و آموزش كشاورزى و منابع طبيعى استان خوزسـتان، سـازمان تحقيقـات،

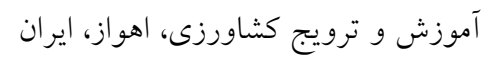

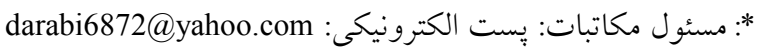


مر احل رشد سيبزمينى رامى توان به بنج مرحله: رشد و توسعه

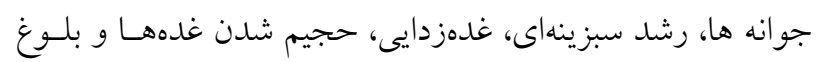

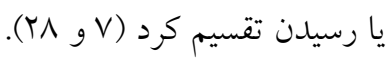

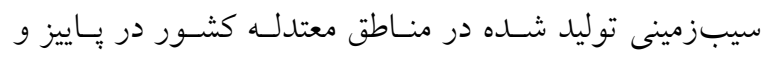

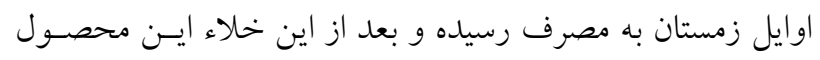

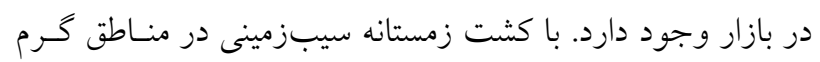

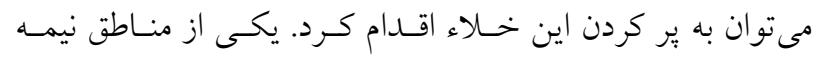

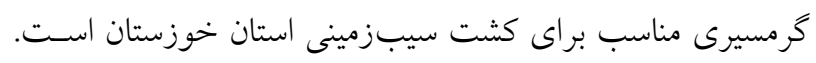
زراعت اين محصول در سالهاى اخير مـورد اسـتقبال كثـاورزان

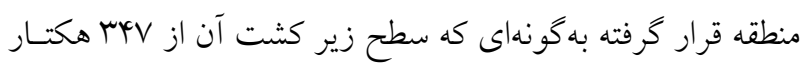

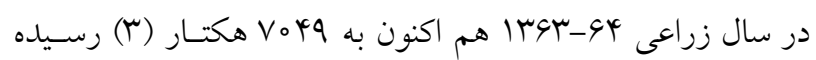

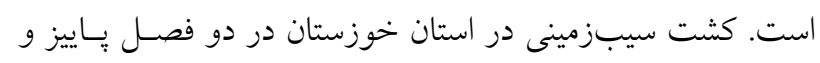

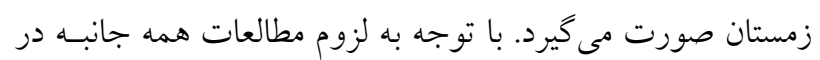

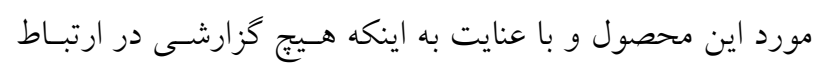
با مطالعه شاخصهاى حرارتى در سـيبزمينسى در كشـور متتشـر

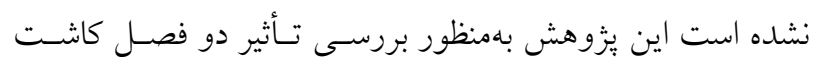

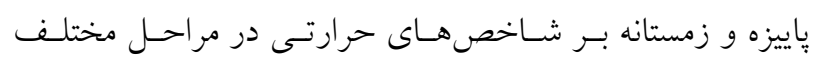

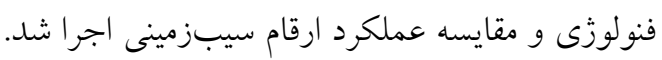

\section{مواد و روشها}

اين تحقيق بهصورت آزمايش اسيليت پلات در زمـان در قالـب

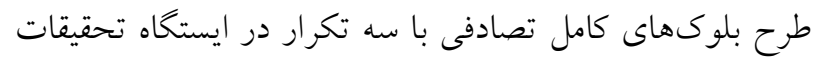

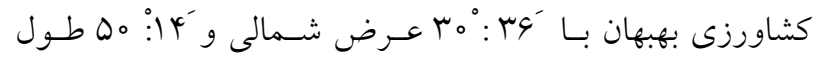

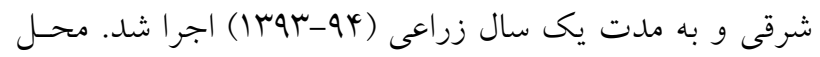

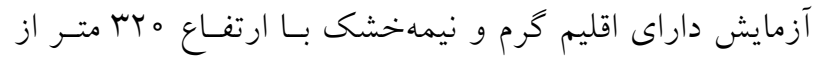

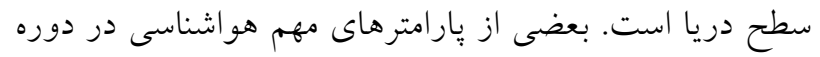

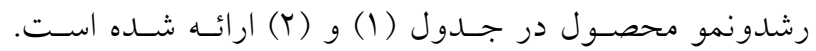
فاكتور اصلى شامل سه رقم سانته، ساوالان و جاويد و فـاكتور فرعى شامل دو فصل كاشت باييزه و زمستانه بود. خصوصيات ارقام مورد بررسى عبارتند از: سانته: متوسط ديررس، فرم بوته نيمهايستاده، رنخ كل سـفيد،

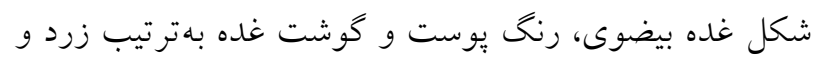
زرد روشن و عمق جشمها سطحى

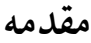

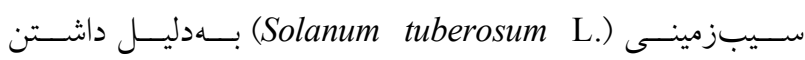

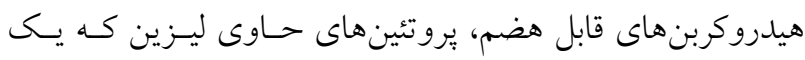

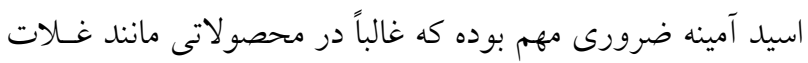

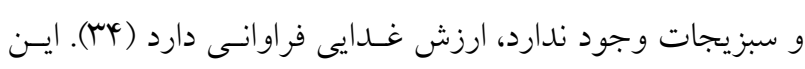

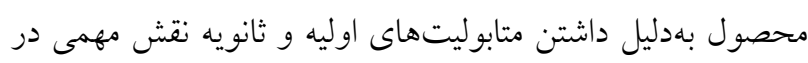

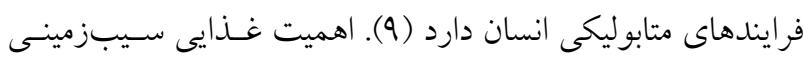

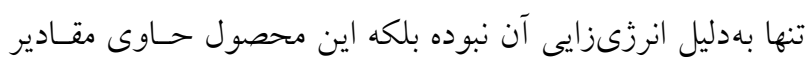

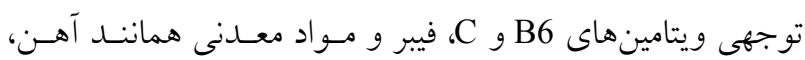

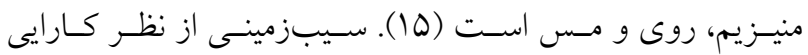

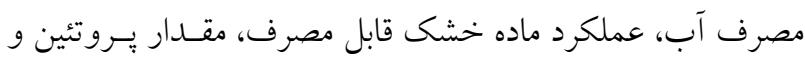
مواد معدنى در واحد سطح بر غلات برترى دارد (Y).

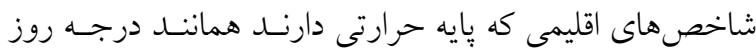

رشد (Growing degree day)، واحسـ هليوترمـال ( Helio thermal

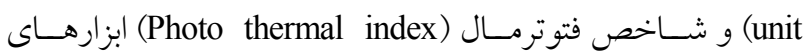

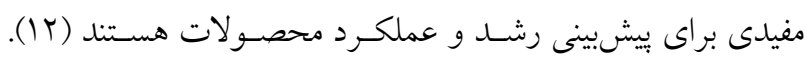

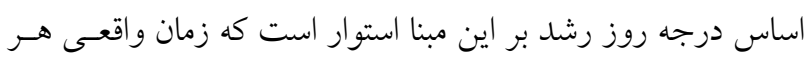

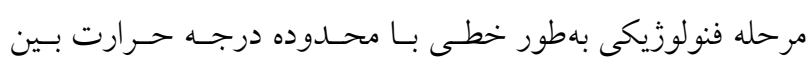

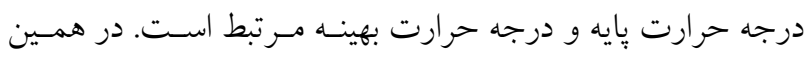

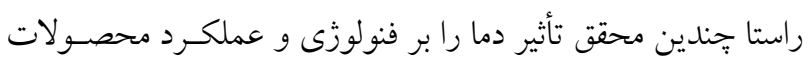

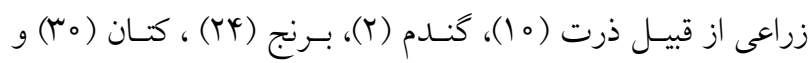
سيبزمينى (19) از طريق شاخص هاى حرارتى كَزارش كـردهانـــ كارايى مصرف دما و نور در تجمع ماده خشكى و عملكـرد كساربرد عملى دارند. كارايى تبديل گرما و نور به ماده خشك به فاكتورهـاى زنتيكى، تاريخ كاشت و نوع محصـول بسـتخى دارد (Y9). بنـابر اين

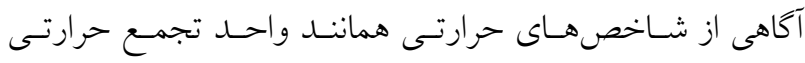
كه در بيشتر منابع از آن بـه عنسوان درجـهـ (Heat summation unit)

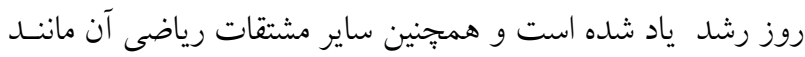

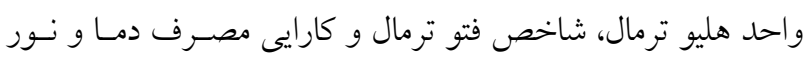

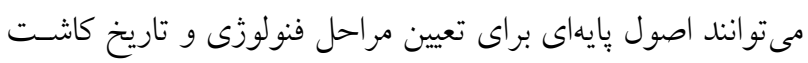

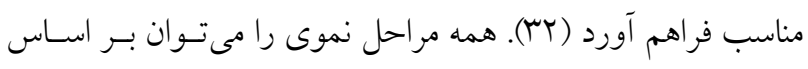

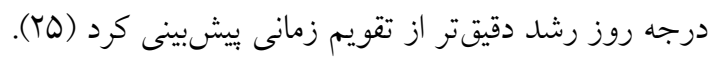


جدول ا. برخى از پارامترهاى هواشناسى ماهيانه در دوره رشدونمو سيبزمينى در دو فصل كشت ياييزه و زمستانه

\begin{tabular}{|c|c|c|c|c|c|c|c|c|}
\hline ارديبهشت & فروردين & 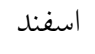 & بهمن & دى & آذر & آبان & مهر & يار امترهو اشناسى \\
\hline$r q / r_{0}$ & $r Y / D \circ$ & $19 / 10$ & $I V / Y_{0}$ & Ir/T & $10 / 40$ & $19 / 40$ & $r \Lambda / r_{0}$ & ميانخين دما (Co \\
\hline ऍN/ノ。 & rq/Vo & $Y Y / l$ & TY & $19 / 1$ & $r \mid / \Lambda$ & $r V / \mu$ & rq/9 & ميانخين دماى حداكثر (C) \\
\hline$r \circ / D_{0}$ & $10 / \mu_{0}$ & $9 / 9$ & $10 / 4$ & $9 / 9$ & $9 / 1$ & $11 / 4$ & $19 / V$ & ميانخين دماى حداقل (Co) \\
\hline $11 / 9 \circ$ & $9 / 90$ & $1 / 1$ & $1 / 9$ & $r / r$ & $\Delta / \Lambda$ & 4 & ir & حداقل مطلق دما (C'C) \\
\hline$Y Y / 4 \circ$ & $r V / q \circ$ & $r \wedge / \Delta$ & $T \Lambda / Y$ & rQ & r9/9 & ry & $r \circ / \Lambda$ & حداكثر مطلق دما (C'C) \\
\hline$\circ / 9 \circ$ & $r \circ / 0 \circ$ & 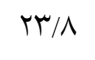 & r & YI/ & $11 \% / \mu$ & ra/o & $14 / 0$ & (ميلى متر) \\
\hline
\end{tabular}

جدول r. طول دوره (روز) و درجه روز رشد مورد نياز مراحل مختلف فنولوزى ارقام سيبزمينى در دو فصل كشت باييزه و زمستانه

\begin{tabular}{|c|c|c|c|c|c|c|c|c|c|c|}
\hline \multicolumn{2}{|r|}{ مجموع } & \multicolumn{2}{|c|}{ حجيم شدن غده } & \multicolumn{2}{|c|}{ غلدهزايى } & \multicolumn{2}{|c|}{ رشد سبزينهاى } & \multicolumn{2}{|c|}{ رشد جوانهها } & تيمار \\
\hline مدت & درجه روز رشد & ملدت & درجه روز رشد & مدت & درجه روز رشد & مدت & درجه روز رشد & مدت & درجه روز رشد & كشت ياييزه \\
\hline 140 & $109 N / 0$ & $M$ & $V \Lambda \mu / \Psi_{0}$ & 10 & $|4| / 90$ & 10 & $10 \% / V 0$ & TV & $\uparrow \wedge \Lambda / \wedge$ & سانته \\
\hline 140 & $109 \Lambda / 0$ & $\wedge \vee$ & WG/4。 & 10 & $1 r V / 1 \circ$ & 10 & $10 \% / 1 \circ$ & r^ & $0.1 / 90$ & ساو الان \\
\hline 140 & $109 \Lambda / 0$ & 91 & $V \backslash \Lambda / \varphi_{0}$ & 10 & $10 \% / r_{0}$ & 10 & $190 / r_{0}$ & ry & $K \Psi Q / V 0$ & جاويد \\
\hline & & & & & & & & & & كشت زمستانه \\
\hline Iry & $19 V \circ / \pi \Delta$ & $\Delta V$ & $\left|Y_{0}\right| / r_{0}$ & 10 & $190 / \mu_{\circ}$ & 10 & (T/MQ & \&V & $4 Q \circ / 40$ & سانته \\
\hline Iry & $19 V \circ / \pi \Delta$ & 99 & $\|\pi\| / T \Delta$ & 10 & $109 / 40$ & 10 & $14 \circ / \Delta D$ & ra & Tr\&/10 & ساو الان \\
\hline Irk & $19 V 0 / \pi \Delta$ & 91 & 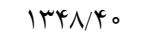 & 10 & $\mid K M / T Q$ & 10 & $191 / V 0$ & re & M19/9r & جاويد \\
\hline
\end{tabular}

كاشت و بقيه در هنگام خاكدهى ياى بوته در اختيار گياهان قـرار

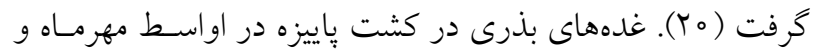
در كشت زمستانه در اواسط دىماه كشت شدند. در زمان كاشـت، غدهها از نظر سن فيزيولوزيكى در شـرايط سـنى جنـــ جوانـهاى،

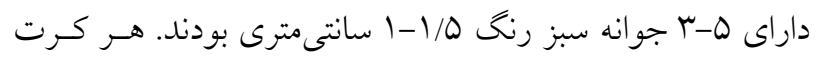
آزمايشى به مساحت ها مترمربع شامل جهار خط كاشت به طـول ينج متر بود. فاصله خطوط كاشت VD سانتى متر و فاصله بوتـههـا

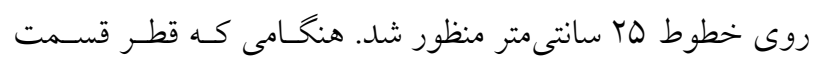
متورم انتهاى استولون دو برابر قطراسـتولون شـــ بـهــــوان زمـان تشكيل غده تلقى شد (N). شاخص هاى زراعى اقليمى بـا اسـتفاده از فرمولهاى زير محاسبه شدند: $\mathrm{GDD}=\Sigma \mathrm{n}[(\mathrm{Tmax}+\mathrm{Tmin}) / r]-\mathrm{Tb}$
ساوالان: نيمهزودرس، فرم بوته ايستاده، رنگ گل بنفش، شكل غده گرد، رنگ يوست غده زرد با لكههاى قرمز در جشــمهـا، رنخ گوشت غده زرد روشن، عمت جشمها سطحى جاويل: متوسط ديررس، فرم بوته ايسـتاده، رنــ گـل سـفيد، شكل غده بيضوى مايل به گرد، رنخ بوسـت و گوشـت غـده بهترتيب زرد و زرد روشن و عمق جشمها سطحى ستى ميزان مصرف كود بـر اسـاس نتـايج آزمسون خـاك و توصسيه مؤسسه تحقيقات خاك و آب صورت كرفت و مقـدار آن در هـر دو فصل كاشت عبارت بود ازه ما كيلوگرم سوبرفسفات ترييل و

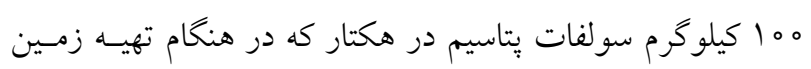
بهطور يكنواخت يخش و با خاك مخلوط شـدند. كـود نيتروزنـهـ

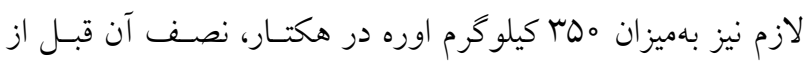


دريافت شده توسط كياه در مرحلـه رشـــ جوانـهــا در كشـت

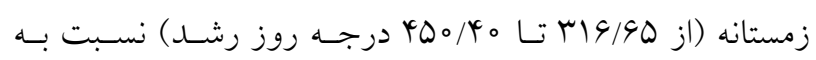

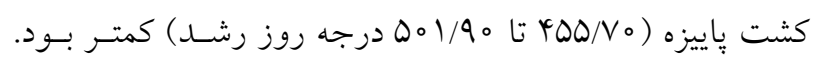

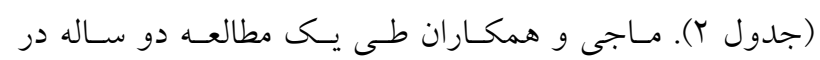

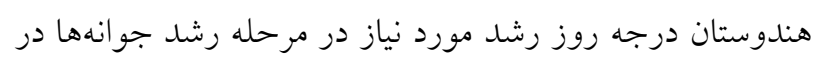

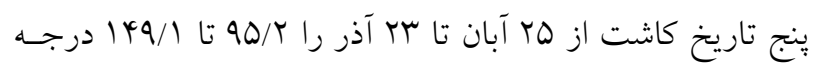
روز رشد گزارش كردند. نتايج مطالعات ورتينگتون و هات باتهين

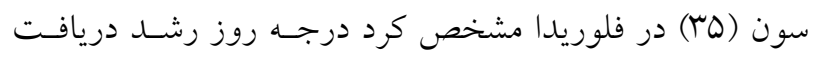

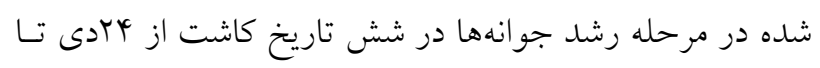

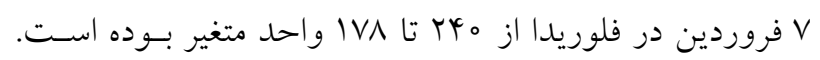

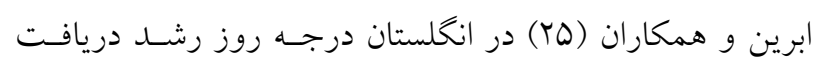

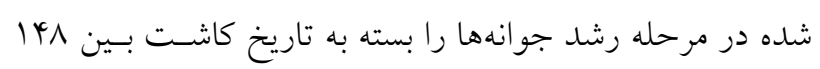

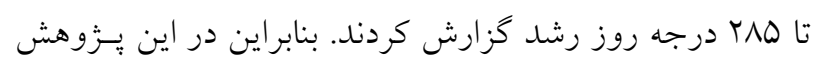

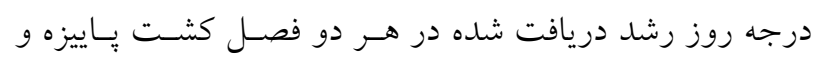

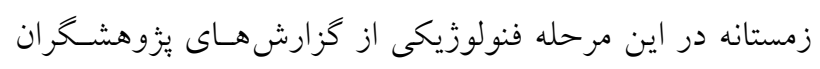

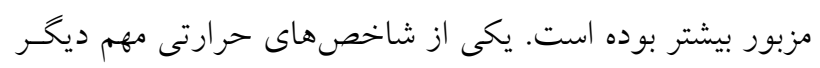

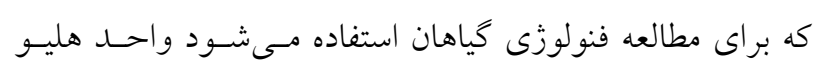

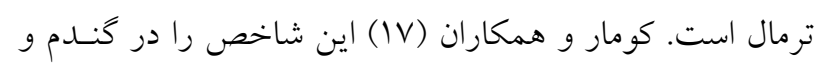

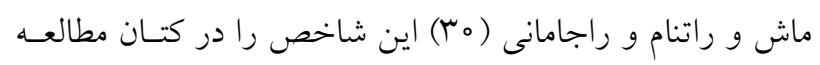

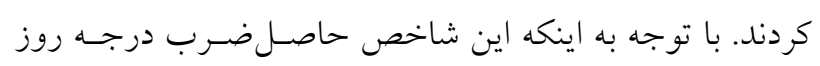

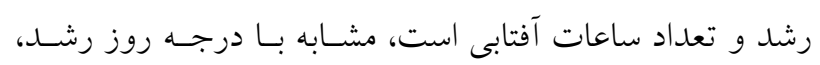
واحد هليو ترمال در هر سه رقم مورد مطالعه در كشـت بــاييزه

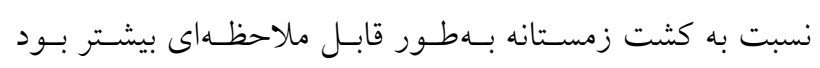
(جدول r) كه دليل اين موضوع بيشتر بودن دما و تعداد ساعات

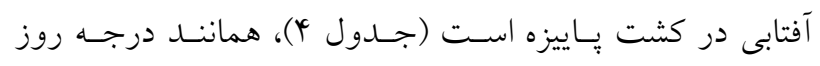
رشد، واحد هليو ترمال در هر دو فصل كاشت و در همــه ارقـام

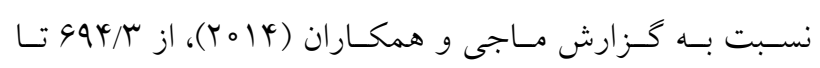

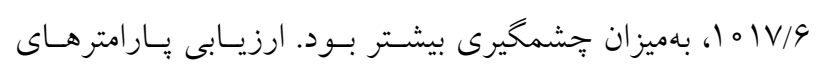

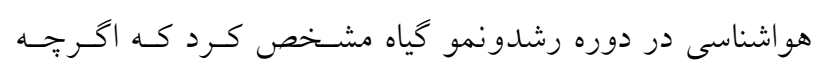

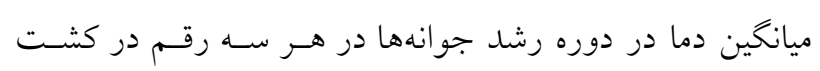

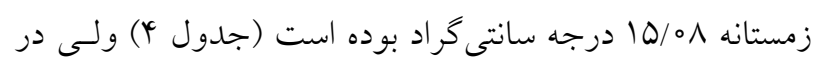
نيمه دوم دى و اوايل بهمن ماه متوسط دماى روزانه نـه تنهـا بـا

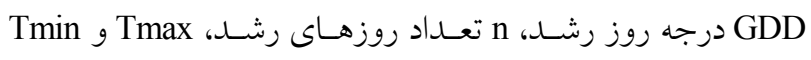

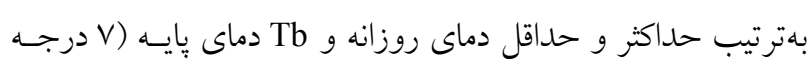

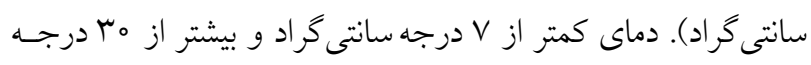

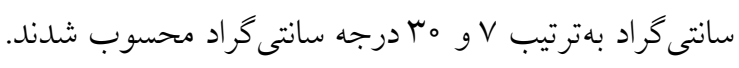
HTU $=$ GDD $\times$ Duration of sun shine hours

و واحد هليو ترمال برحسب ساعات آفتابى در درجه روز

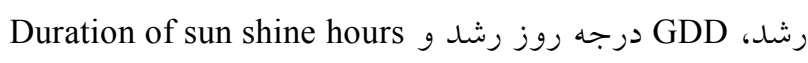
دوره ساعات آفتابى درجي روز

HTUE $=$ Yield $/$ HTU

كارايى مصرف هليـو ترمـال بـر حسـب كيلـوكرم در

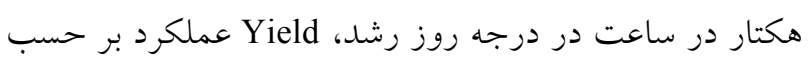
كيلو كرم در هكتار و GDD درجه دور دوز دوز روند

TUE $=$ Yield/GDD

كارايى مصرف حرارت بـر حسـب كيلـو گرم در هكتـار

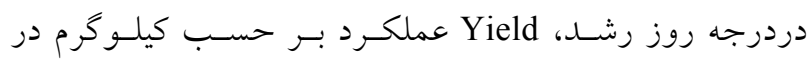

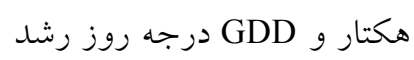

PTI $=$ GDD/Growth days

شاخص فتو ترمال بـر حسبب درجـه روز رشـــ در روز،

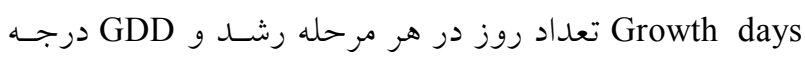
روز رشد (ه ا، 19، اس وه هـ). يكى هفته قبل از برداشت اندامهاى هوايى قطع و غدهـــا در

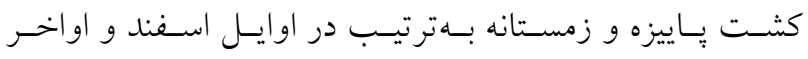

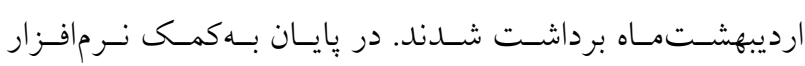

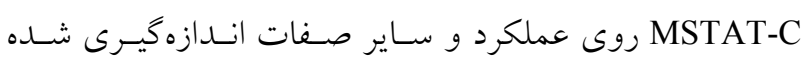
تجزيه واريانس ساده صورت كرفت و ميانكينها به كمك آزمون : جند دامنهاى دانكن مقايسه شدند.

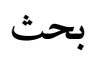

اثر فصل كاشت بر شـاخصهـاى حرارتسى در مراحسل مختلف فنولوزيكى

رشد جوانهها

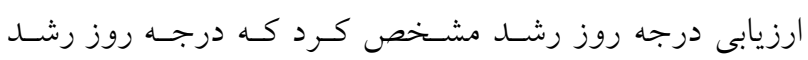


جدول r. واحد هليو ترمال (برحسب ساعت در درجه روز رشد) و شاخص فتو ترمال (برحسب درجه روز رشد در روز)

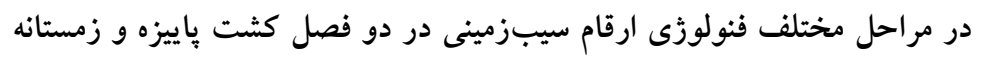

\begin{tabular}{|c|c|c|c|c|c|c|c|c|c|c|}
\hline \multicolumn{2}{|c|}{ مجموع } & \multicolumn{2}{|c|}{ حجيم شدن غده } & \multicolumn{2}{|c|}{ غدهزايى } & \multicolumn{2}{|c|}{ رشدسبز ينهاى } & \multicolumn{2}{|c|}{ رشد جوانهها } & \multirow{2}{*}{ كشت باييزه } \\
\hline شاخص & واحد & شاخص & واحد & شاخص & واحد & شاخص & واحد & شاخص & واحد & \\
\hline فتو ترمال & هليوترمال & فتو ترمال & هليوترمال & فتوترمال & هليوترمال & فتوترمال & هليوترمال & فتوترمال & هليوترمال & رقم \\
\hline$r \& / V Q$ & $1 / r / \Delta / \Delta \Delta$ & $\Lambda / q_{0}$ & $4990 / 9 \mathrm{~V}$ & $9 / 44$ & $(N K T / 9)$ & $10 \pi 1$ & $1790 / 09$ & $\left.|N|\right|^{\circ}$ & $Y \backslash \wedge Q / \circ Y$ & سانته \\
\hline YAIVO & $1 / \pi / \Delta / \Delta 0$ & N/AT & rarg/4V & $9 / 14$ & $\Lambda \uparrow \& / 01$ & $10 / \pi_{0}$ & $|r| \circ / V$ & IV/ar & $\mu r \circ g / N D$ & ساو الان \\
\hline YQNO & $1 / \pi / \Delta / \Delta \Delta$ & N/91 & $01 V V / 9 V$ & $N / r)$ & $q 4 \circ \mu \circ$ & $11 / 01$ & IrTo/Dr & $\mid N / \Delta V$ & $r q \mu \circ / v_{0}$ & جاويد \\
\hline & & & & & & & & & & كشت زمستانه \\
\hline$Y N / 9 \Lambda$ & $|r Q| N / \circ D$ & $r Y / \circ \Lambda$ & $A V Y Y N \mid$ & $1 r / 0 r$ & $\mid r V \% / 0 V$ & $N / T r$ & $11 \% N / 99$ & $9 / 0 \Lambda$ & $r r V \psi / r 1$ & سانته \\
\hline$Y N / Q \Lambda$ & $|r \Delta| N / \circ D$ & IV/IY & $949 . / 90$ & $10 / 4 \pi$ & $|\mathrm{krd} / 9|$ & $9 / \pi V$ & $V \circ \circ / r Q$ & $N / r^{\prime}$ & $r \circ 91 / \Delta r$ & ساو الان \\
\hline$Y \wedge / q \Lambda$ & $|r \Delta| N / 00$ & $19 / \Lambda r$ & $9091 / 41$ & $Q / Q V$ & $\mid r 9 \Delta / 4 \pi$ & $10 \mathrm{NA}$ & $0 \circ V / T)$ & $N / \Lambda_{0}$ & TODY & جاويد \\
\hline
\end{tabular}

جدول f. ميانخين دما (درجه سانتى گراد) و تعداد ساعات آفتابى در مراحل مختلف فنولوزى ارقام سيبزمينى در دو فصل كشت بإييزه و زمستانه

\begin{tabular}{|c|c|c|c|c|c|c|c|c|}
\hline \multicolumn{2}{|c|}{ حجيم شدن غده } & \multicolumn{2}{|c|}{ غدهزايى } & \multicolumn{2}{|c|}{ رشد سبزينهاى } & \multicolumn{2}{|c|}{ رشد جو انهها } & \multirow{2}{*}{ كشت پياييزه } \\
\hline ساعات آَتابى & دos & ساعات آَتابى & Lد & ساعات آفتابى & los & ساعات آفتابى & los & \\
\hline $9 / 1 \mathrm{r}$ & $10 / 09$ & $9 / 4 T$ & $10 / 99$ & $1 / \omega_{0}$ & $|V / \mu|$ & N/OT & $r Q / 10$ & سانته \\
\hline $9 / 01$ & $10 / 10$ & $9 / 9 \mathrm{~V}$ & $10 / 90$ & $N / M$ & $|V / r|$ & $N / \Delta Q$ & $r \varphi / q r$ & ساوالان \\
\hline \multirow[t]{3}{*}{$9 / 9 \mathrm{~V}$} & $14 / 91$ & $9 / 11$ & $|V / r|$ & $1 / 19$ & $1 N / 10$ & $\Lambda / N \Delta$ & $r Q / Q V$ & جاويد \\
\hline & & & & & & & & كشت زمستانه \\
\hline & & & & & & & & رقم \\
\hline $9 / 99$ & YN/II & $9 / 01$ & $Y 0 / 0 Y$ & $9 / \circ V$ & $14 / 04$ & Q/AT & $|0 / 9|$ & سانته \\
\hline $9 / 9 \mathrm{~V}$ & YV/IV & $Q / T V$ & IV/FT & $\Delta / \Gamma \Lambda$ & $10 / A V$ & $9 / 10$ & $10 / 11$ & ساو الان \\
\hline $9 N r$ & rg/NT & $9 / 09$ & $19 / 00$ & $r / \Delta V$ & $19 / 90$ & $9 / 09$ & $1 \% / Q T$ & جاويد \\
\hline
\end{tabular}

سانتى گراد، (جدول ( آ) نسبت به دماى بهينه براى رشد جوانههـا،

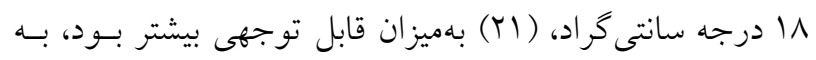

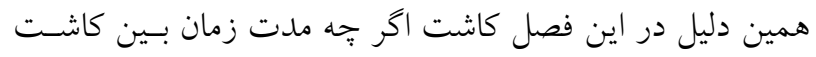
تا سبز شدن غلده بهطور معنى دارى از كشت زمستانه كمتسر بـود

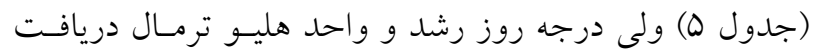

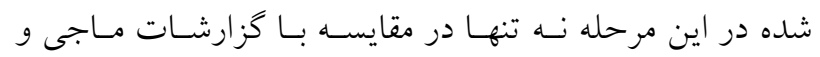

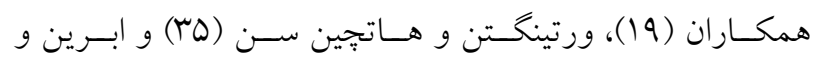

صفر فيزيولوزى سيبزمينى، هفت درجه سـانتى گـراد، اخـتلاف

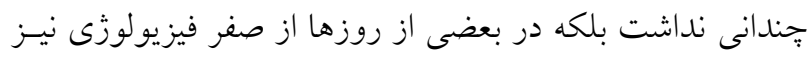
كمتر بود. بنابراين در كاشت زمستانه يايين بـودون دمـا در اوايـل رشدونمو محصول سبب طولانى شدت مدت زمان اين مرحلـه،

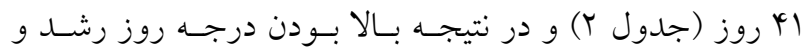
واحد هليو ترمال دريافت شده توسط گياه شد. در كشت يـاييزه

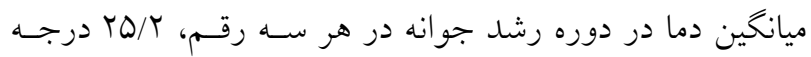


جدول ه. نتايج مقايسه ميانگين تعداد روز تا سبز شدن، تعداد ساقه، عملكرد كل، تعداد غده در بوته، متوسط وزن غده، كارايى مصرف

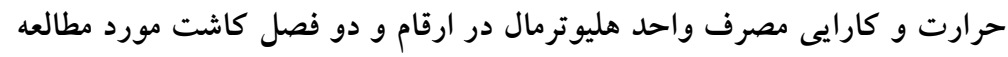

\begin{tabular}{|c|c|c|c|c|c|c|c|}
\hline كارايى مصرف واحد هليو ترمال & كارايى مصرف حرارت & وزتوسط & غده دراد & 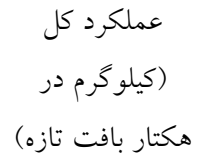 & تعداد ساقه & سبز شدن تان & تيمار \\
\hline & & & & & & & رقم \\
\hline $1 / \mathrm{V}^{\mathrm{c}}$ & $\mid r / \circ Y^{b}$ & $V Y / \Delta r^{a}$ & $\Delta / q \mu^{b}$ & $Y \circ \wedge Y_{\circ} \circ$ & $r / \Lambda^{a}{ }^{a}$ & $r V / I V^{a}$ & سانته \\
\hline $1 / \Lambda \mu^{b}$ & $|r / 9|^{b}$ & $V r / V r^{a}$ & $0 / 4 \circ b$ & TrMG०b & $r / r q^{a}$ & س & ساو الان \\
\hline$r / T \mu^{a}$ & $10 / 10^{a}$ & $9 \mathrm{~V} / 9 \mathrm{G}^{\mathrm{a}}$ & $V / 9 V^{a}$ & YVIO० a & $r / M^{a}$ & $r_{0} / l V^{b}$ & جاويد \\
\hline$r / T \Lambda^{a}$ & $19 / 40^{\circ}$ & $99 / \circ \mathrm{V}^{\mathrm{a}}$ & $V / M V^{a}$ & rQAYOa & $r / 4 y$ a & $r \& / 4 Y^{\circ}$ & پاييزه \\
\hline $1 / 09 \mathrm{~b}$ & $10 / v \circ b$ & $V \Psi / V \mathcal{C}^{\mathrm{a}}$ & $0 / 4)^{b}$ & $r / \circ \Lambda_{0} b$ & $r / Y I^{\text {a }}$ & $\left.4\right|^{\text {a }}$ & زمستانه \\
\hline
\end{tabular}

ميانكينهاى هر ستون كه حداقل در يك حرف مشترك هستند، براى رقم و فصل كاشت بهترتيب در سطح احتمال يك و ينج درصد اختلاف معنى دارى ندارند.

همكاران (TO) بلكـه حتسى در مقايسـه بـا كشـت زمسـتانه نيـز رشد سبزينهاى

در سيبزمينى مدت زمان مرحله رشـــ سـبزينهاى نقـش بسئسيار

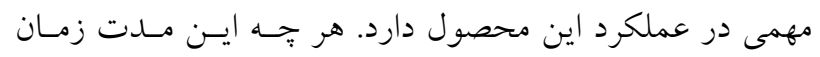

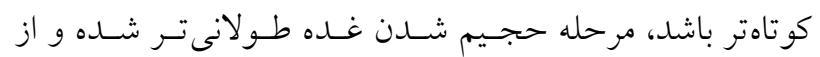
طرف ديخر اندام هاى هوايى به عنوان يك منبـع رقابـت كنتــده

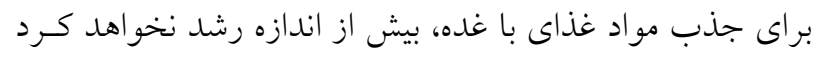

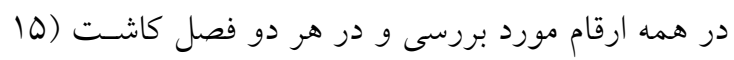

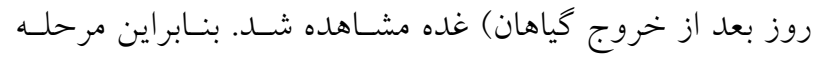
رشد سبزينهاى، در هر دو فصل كشت ياييزه و زمستانه 10 روز بود. يرويزى و همكاران (TV) كزارش كردند كه در كشت بهاره

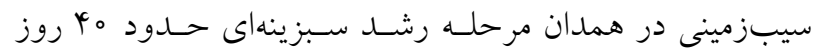
است، بنابراين مىتوان نتيجه گيرى كرد مرحله رشد سبزينهاى در

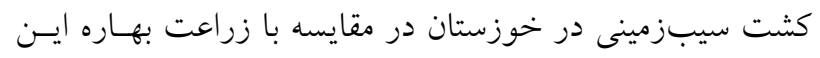

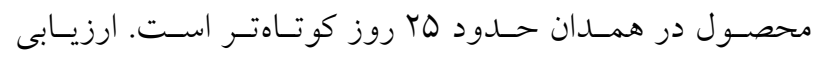
بارامترهاى اقليمى نشان داد كه ميـانخين دمـاى روزانـه در دوره

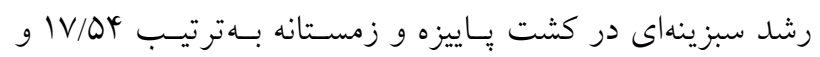

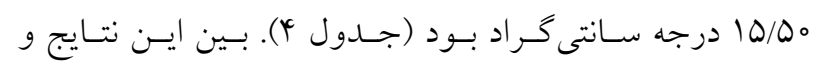

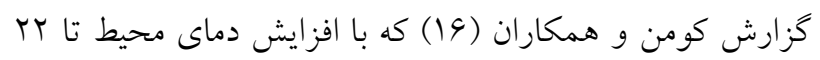

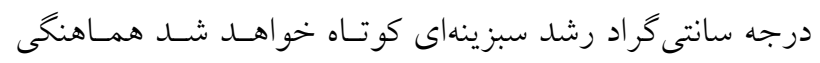

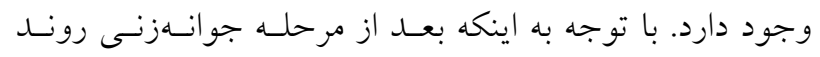

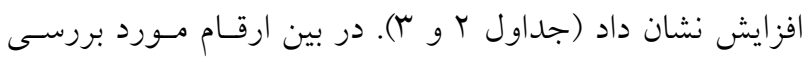

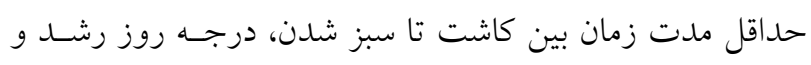

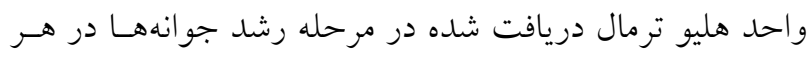

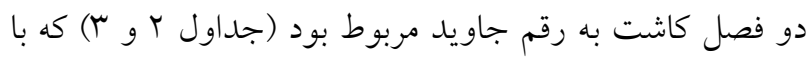
توجه به متفاوت بودن نوع تنشهاى دمايى در دو فصل كاشـت

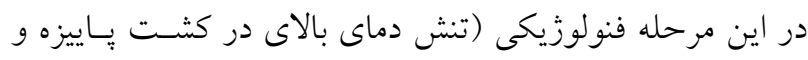

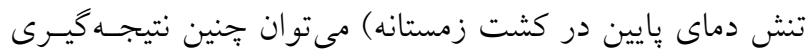
كرد در رقم جاويد تحمل تنش دماهاى نامساعد در مرحله رشد

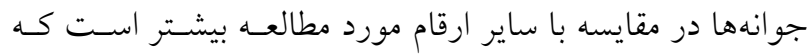

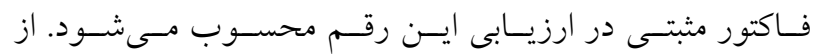

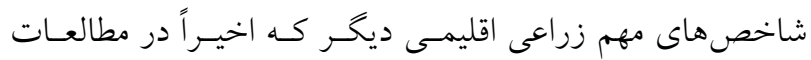

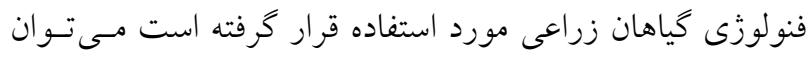

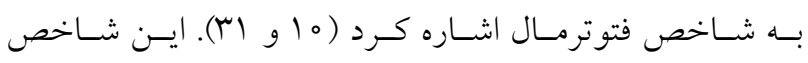

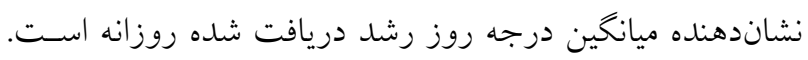

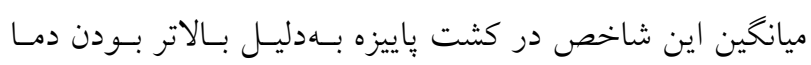

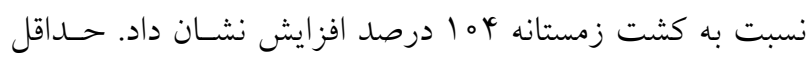
شاخص فتو ترمـال در هـر دو فصـل كثـت زمسـتانه و وِـاييزه

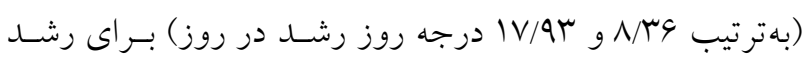
جوانها به رقم ساوالان مربوط بود (جدول r). 
اين آزمايش ها روز بعد ازسبز شدن، كياهان وارد ايـن مرحلـه

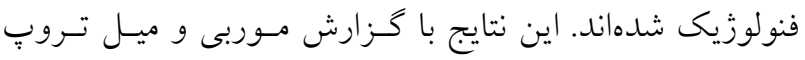
(Tr) كه مناسبترين شرايط اقليمى براى غدهزايى دماى ه ا تـائ

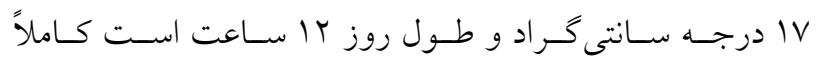

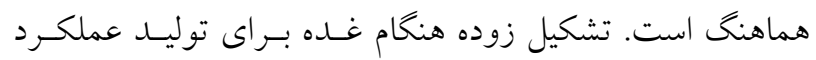

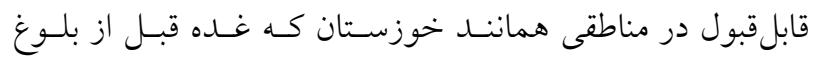

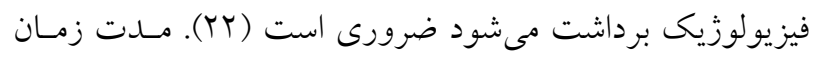

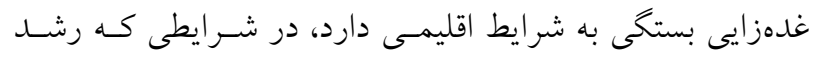

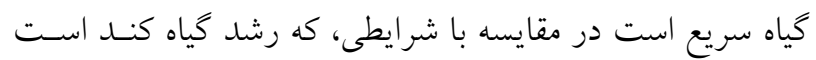

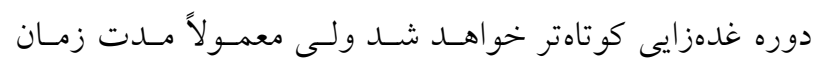
غدهزيى در سيبزمينى بين دو تـا شـش هفتـه در نظـر كرفتـه مىشود (TO) على (ro)

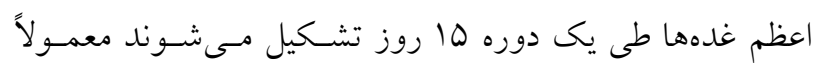

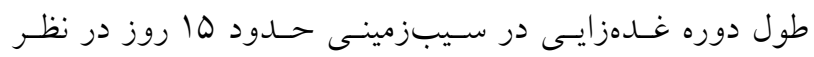

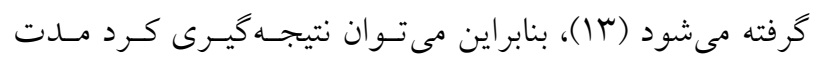

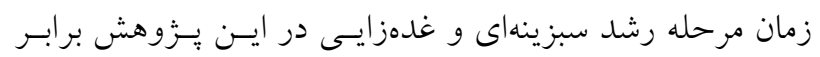

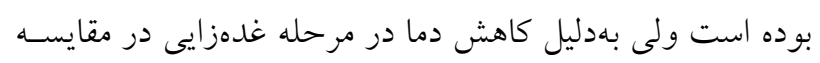

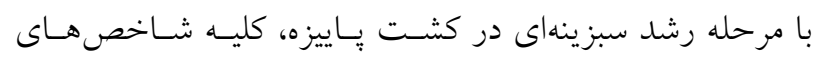

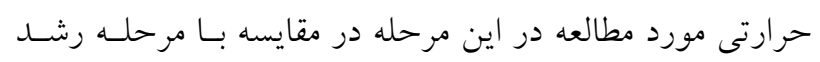

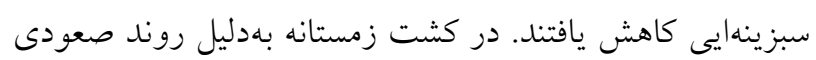

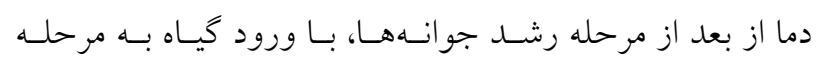

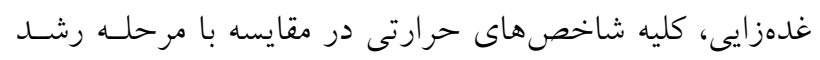

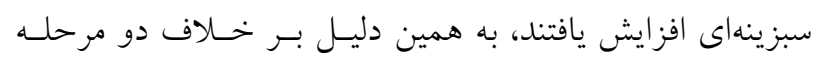

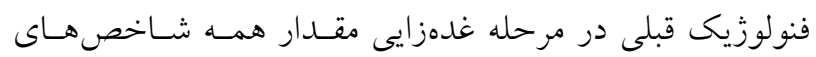

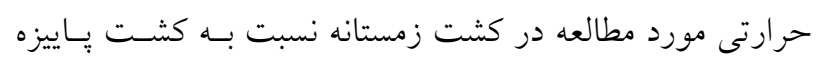
بيشتر بود (جداول r و بَ).

حجيم شدن غده سـرعت و مـــت حجـيم شـــن غـده تعيـين كنــده عملكــــد سيبزمينى است ولى مدت حجيم شدن در مقايسـه بـا سـرعت حجيم شدن نقش مهمترى در تعيين عملكرد اين محصـول ايفـا

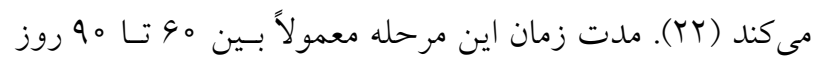

تغييرات درجه حرارت هوا در كشت هياييزه و زمستانه بهترتيسب

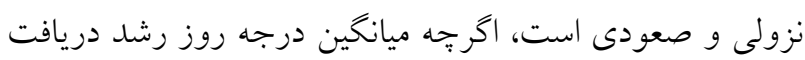

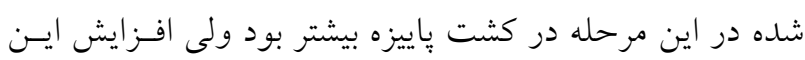

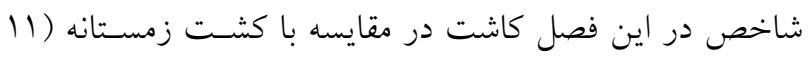

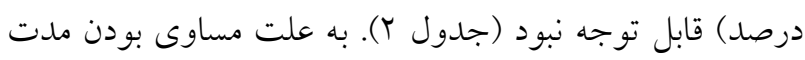

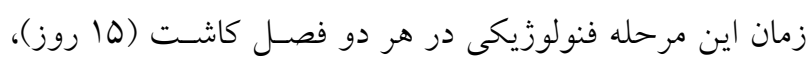

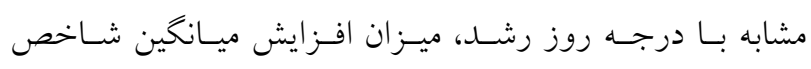

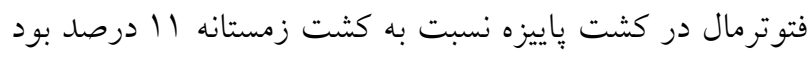
(جدول r). با عنايت به مساوى بودن مدت زمان اين مرحلـه در

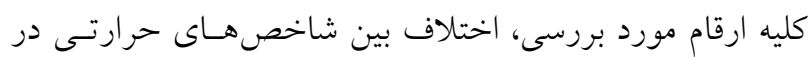

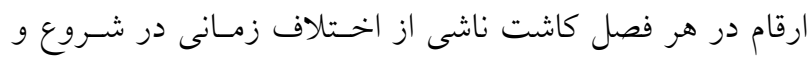

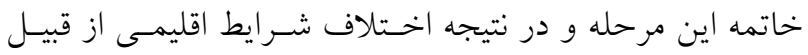

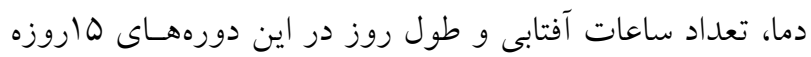

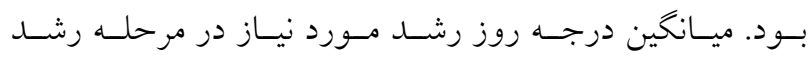

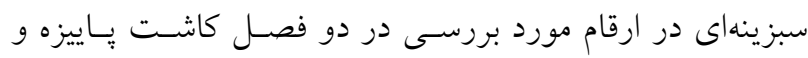

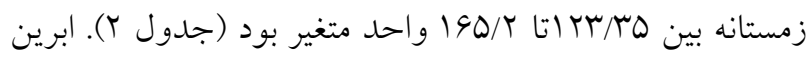

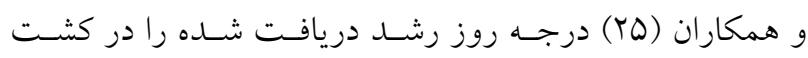

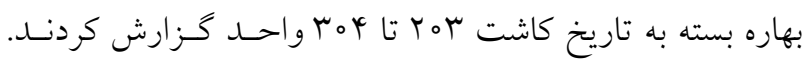

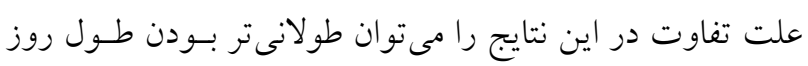

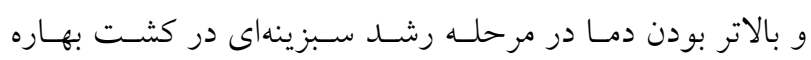

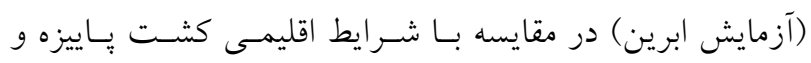
زمستانه اين محصول در خوزستان نسبت داد.

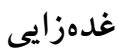

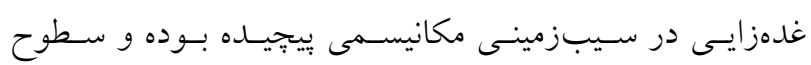

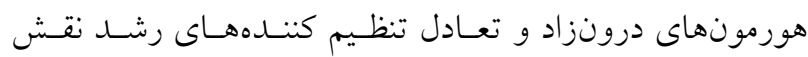

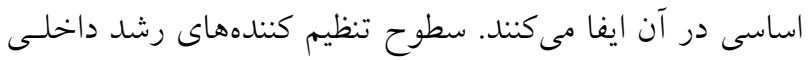

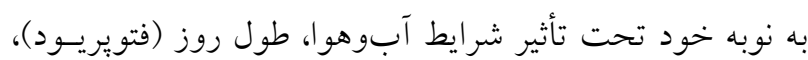

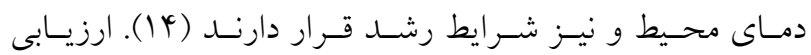
يارامترهاى اقليمى مشخص كرد كه در هر دو فصل كاشت مورد

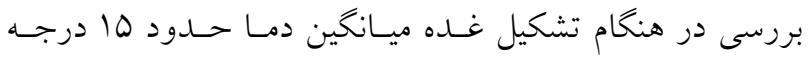

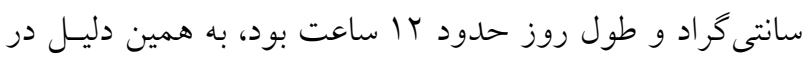


است. تعداد ساعات آفتابى مؤثر در فتوسنتر و دماى روزانه تأثير بلوغ

بهدليل بالا رفتن دما از اواسط ارديبهشت، برداشـت در خوزسـتان

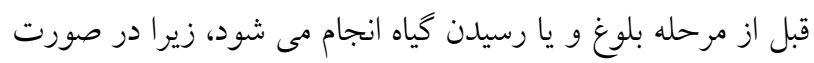

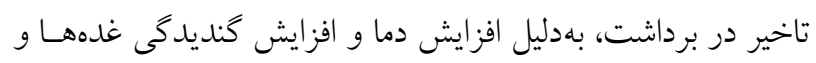

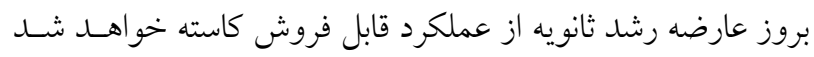

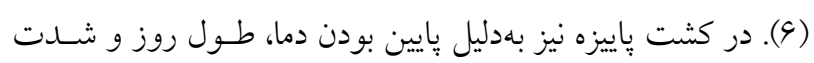

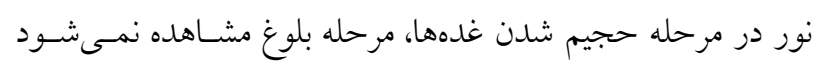

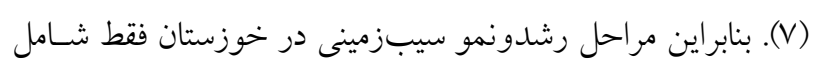

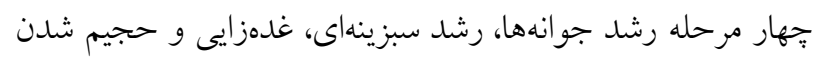

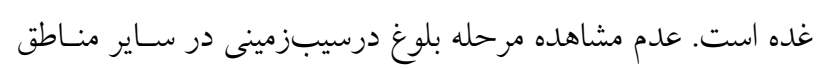
كرمسيرى نيز گزارش شده است (1).

خصوصيات زراعى و عملكرد

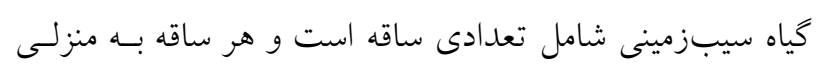

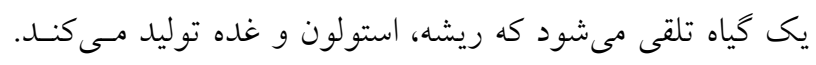

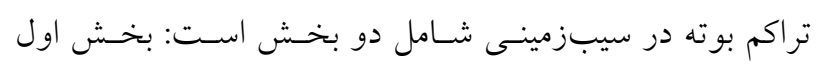

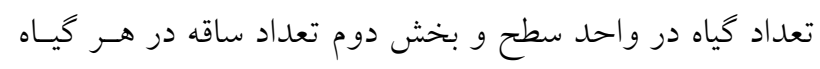

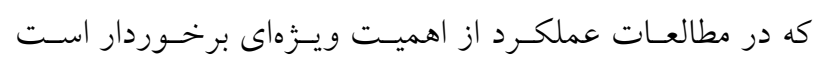
(YN)

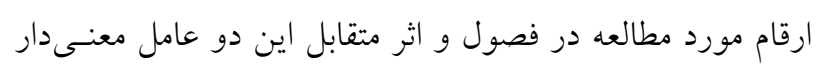

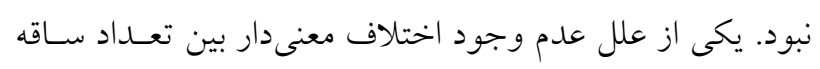

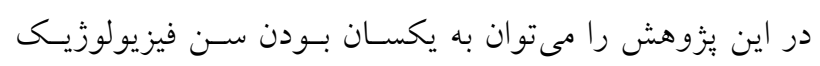

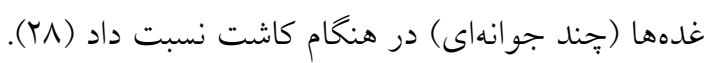

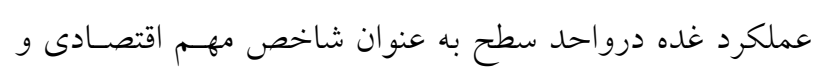

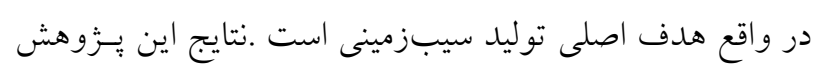

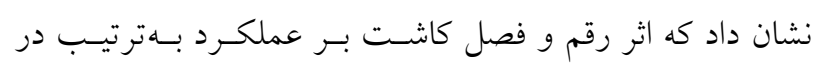

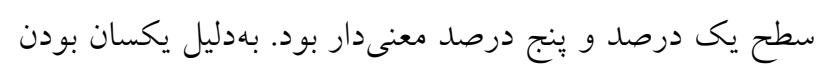

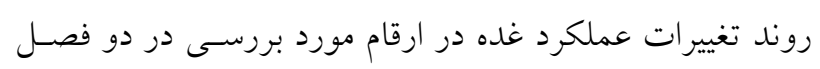

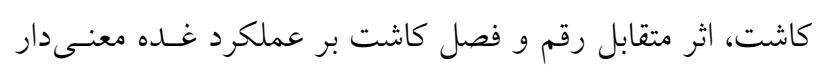

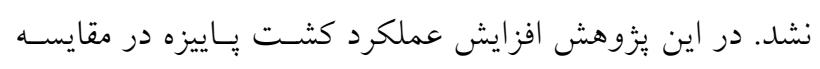

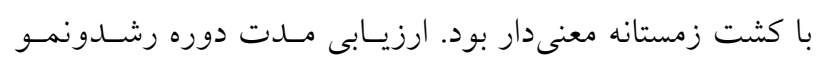

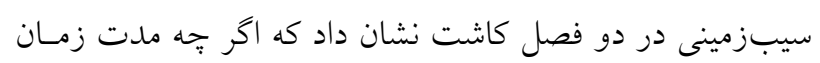

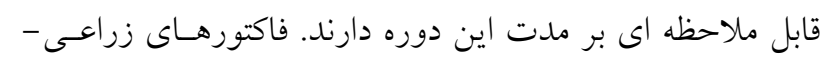

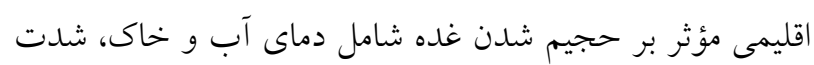

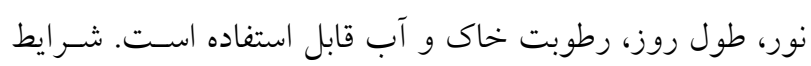

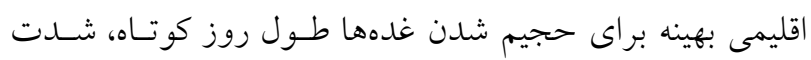

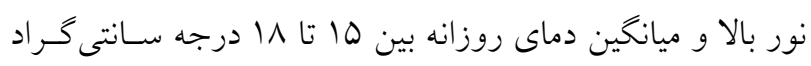

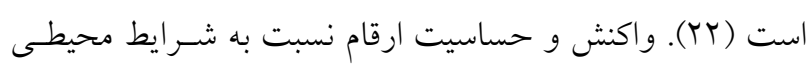

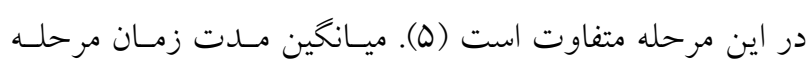

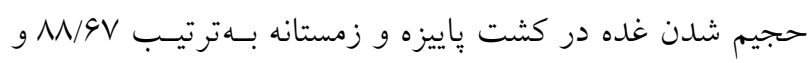

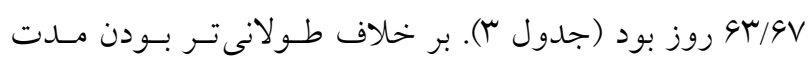

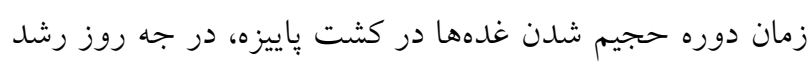

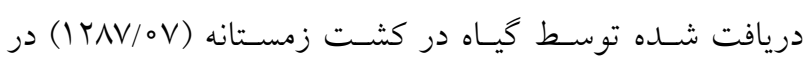

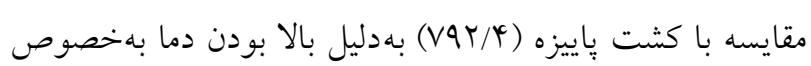

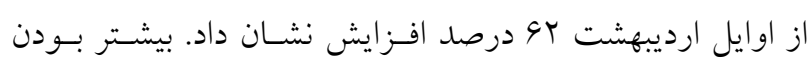

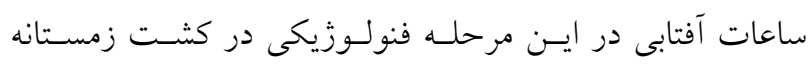

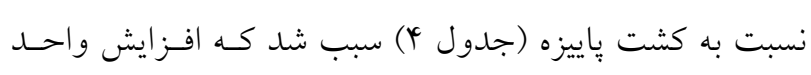

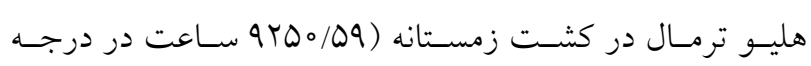

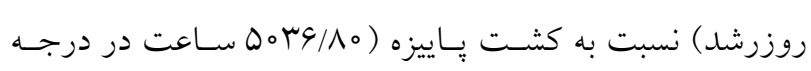

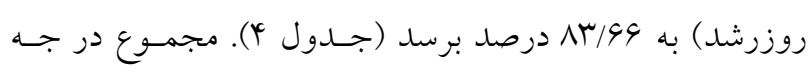

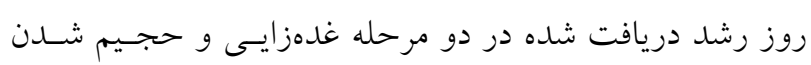

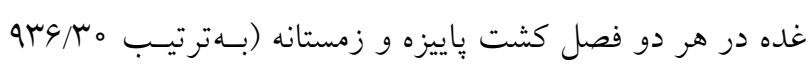

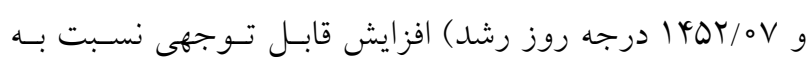

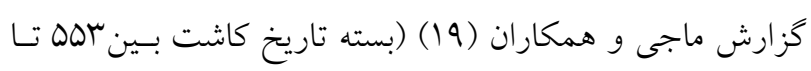

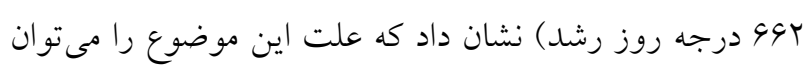

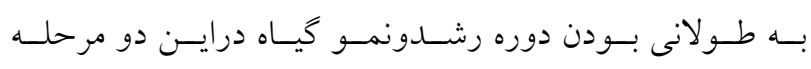

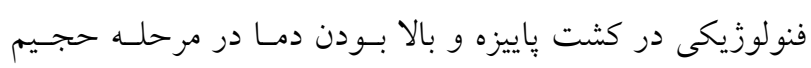

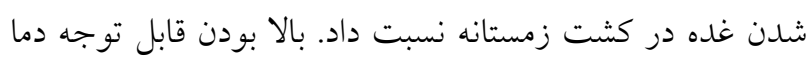

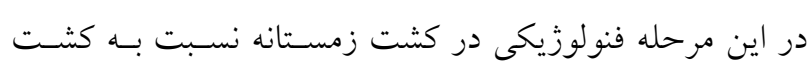

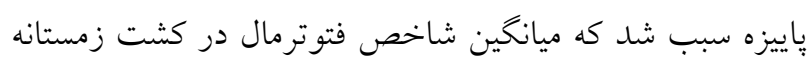

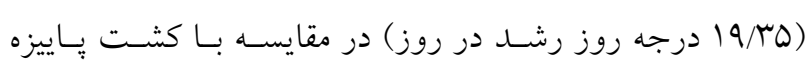

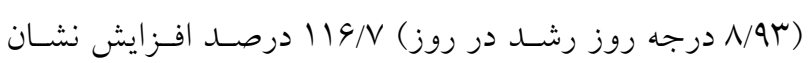
دهد (جدول r). (ب) 
غدههـا در هـر دو فصـل كاشـت نسـبت داد. در كشـت يـاييزه

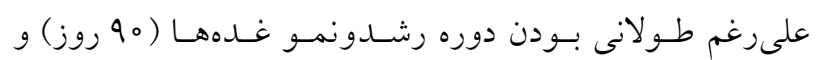

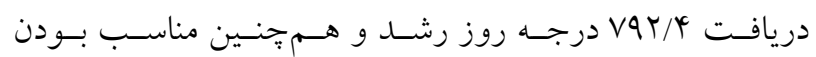

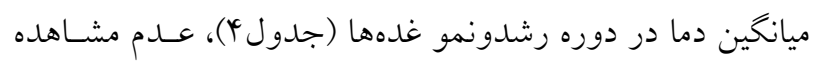

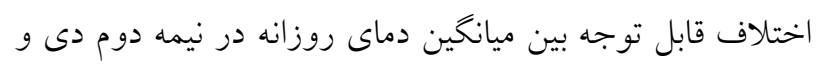

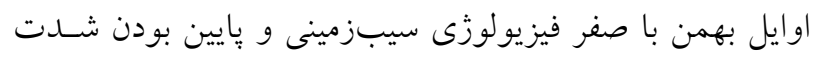
و مدت نور در بخش قابلتوجهى از دوره حجيم شدن غــههــا سبب مىشوند كه غدهها نتواند به حلداكثر حجم و انداره خـود برسند و در نتيجه عملكرد سيبزمينى در اين فصـل كاشـت در منطقه بالا نباشد. در كشت زمستانه نيـز علسىرغـم كـافى بـودن

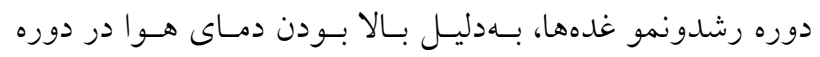

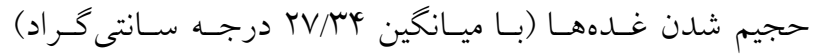
عملكرد محصول بايين بود. بايين بودن عملكرد سيبزمينى در

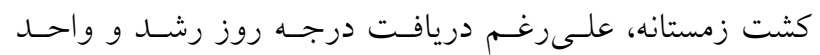
هليوترمال قابل توجه، منعكس كننده رانـدمان يـايين اسـتفاده از

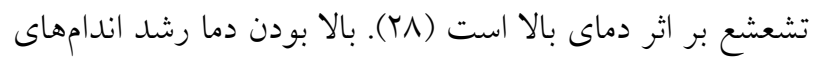

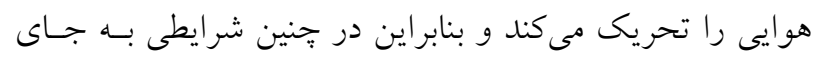

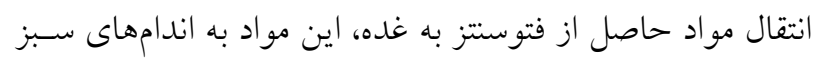

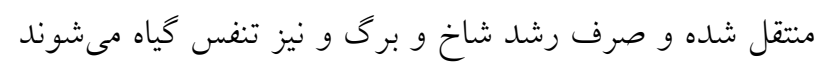

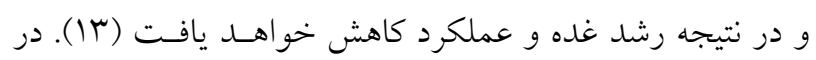

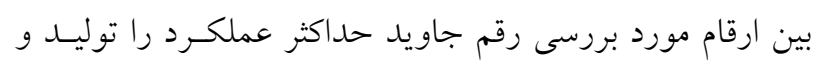
بر دو رقم ديغر در سطح يك درصد برترى داشت (جــدول ه).

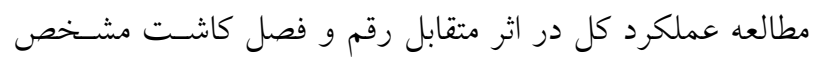

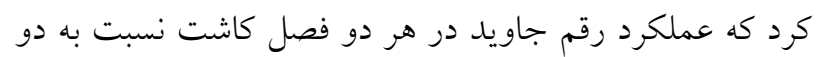

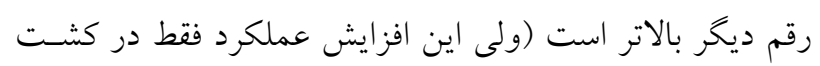

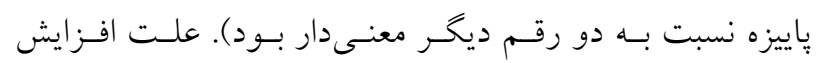

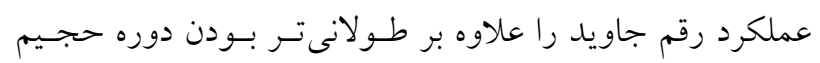

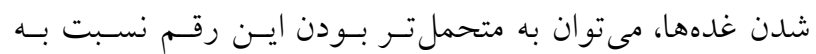

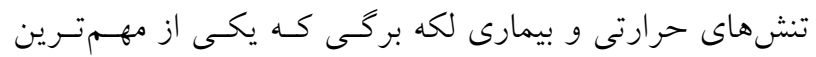
بيمارىهاى سيبزمينى در هر دو فصل كاشت است، نسبت داد. وجود اختلاف در تحمل تنش دماى بالا در ارقام سـيبزمينى

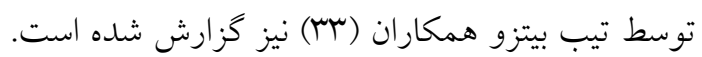

دوره رشدونمو كياه در كشت باييزه نسـبت بـه كشـت زمسـتانه

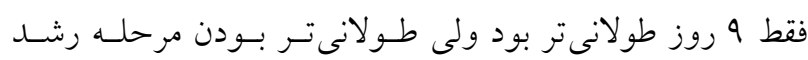
جوانهها در كشت زمستانه نسبت بـه كشـت بـاييزه (

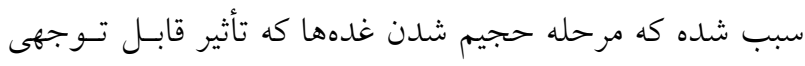

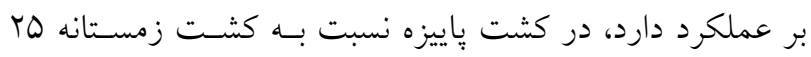
روز طولانىتر شود (جدول Y). علاوه بر طولانىتر بودن مرحله حجيم شدن غدهها در كشت پاييزه، مساعدتر بودن دمـا در دوره

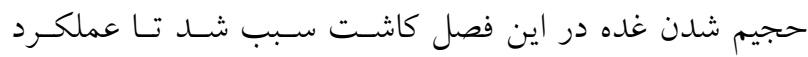
كشت باييزه نسبت به كشت زمستانه افزايش معنى دارى را نشان دهد (جدول Q). علىرغم كو تاهتر نبودن دوره رشدونمو گيساه در

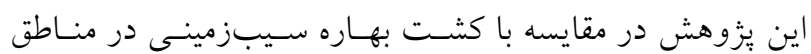

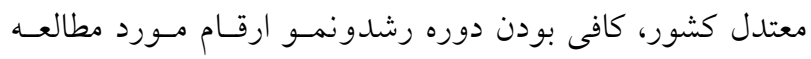

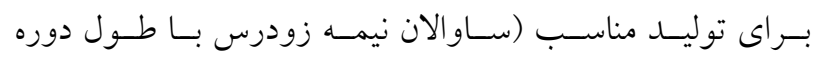
رشدونمو •جا روز و ارقام سانته و جاويد نيمه ديررس با طول

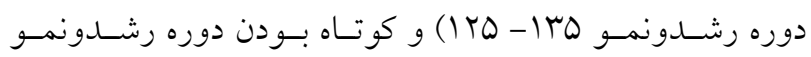

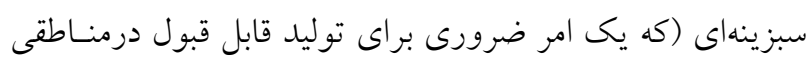

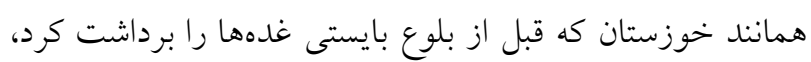

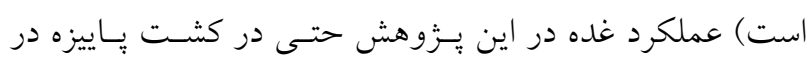

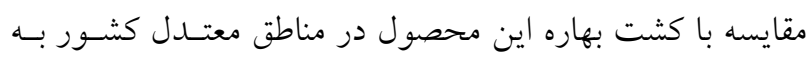

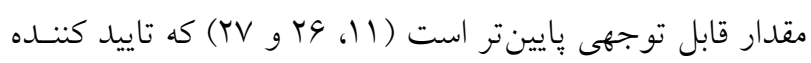

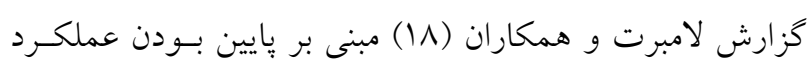

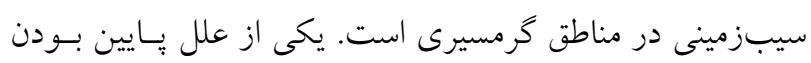

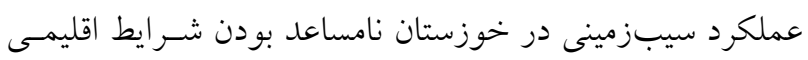
در مرحله رشد جوانهها است كه ضمن طولانى شدن ايسن دوره

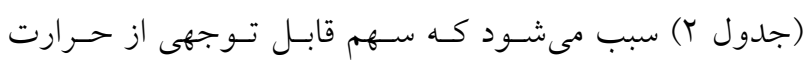

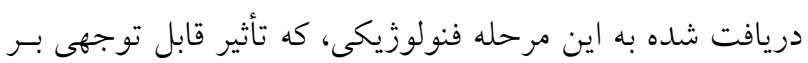

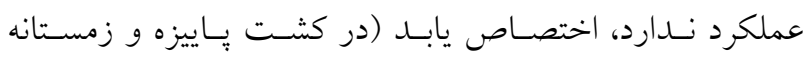

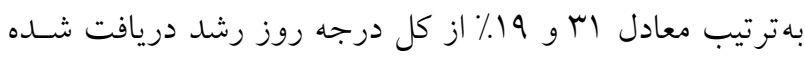

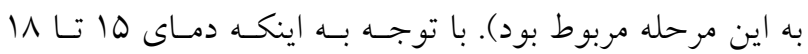

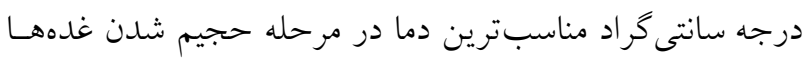

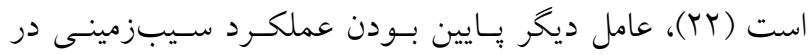
خوزستان را مىتوان به نامساعد بودن دما، در دوره حجيم شدن 


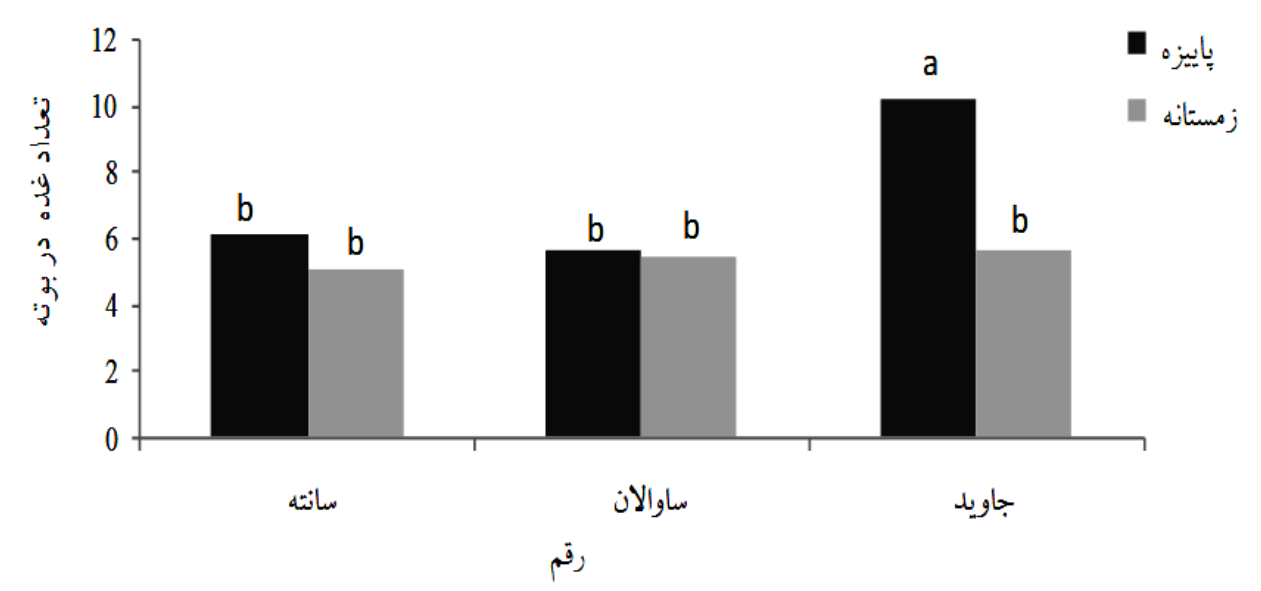

شكل ا. مقايسه ميانكين تعداد غده در بوته در ارقام مورد مطالعه در دو فصل كاشت باييزه و زمستانه. ميانخين هاى هر ستون كه حداقل در

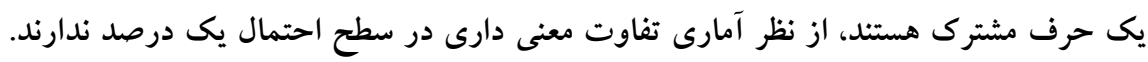

كه اثر فصل كاشت و رقم بر اين صفت معنىدار نبـود ولسى اثـــ

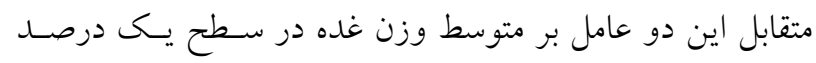

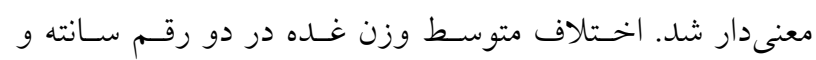

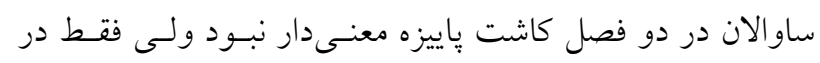

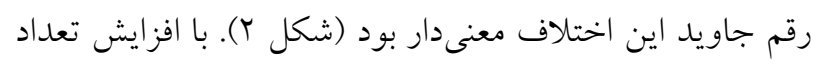

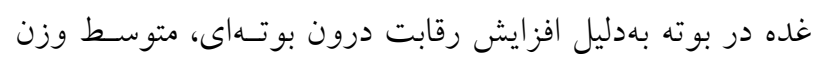

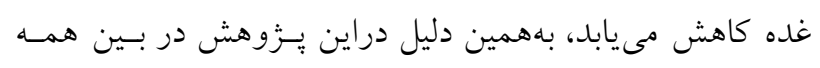

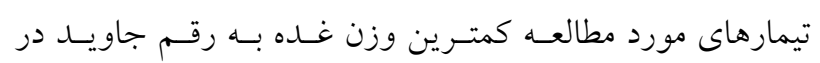

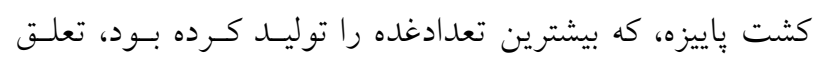

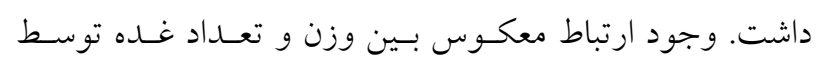

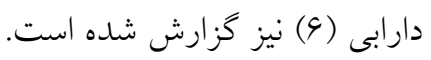

كارايى مصرف حرارت و واحد هليو ترمال

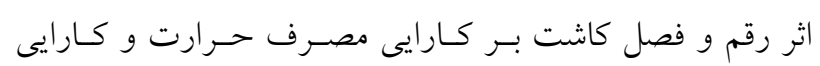
مصرف واحد هليو ترمال بهترتيب در سطح يك درصــ و و وـنسج

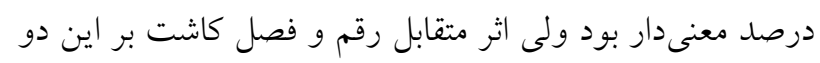

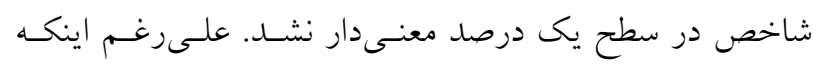

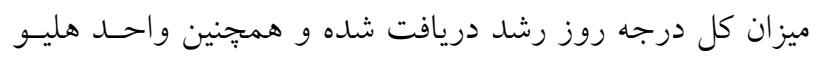

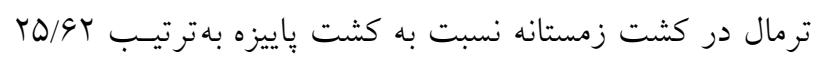

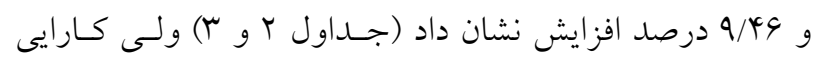
مصـرف حسرارت و كـاريى مصــرف واحســ هليـو ترمـال در
تعلداد غده در بوته بستكى به رقم، سن فيزيولوزيكى غلده بــرى، تعداد ساقه و شرايط محيطى در ابتداى فصل رشد دارد. شـرايط

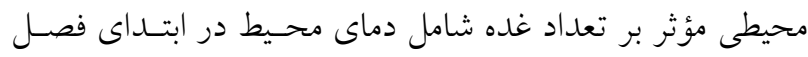

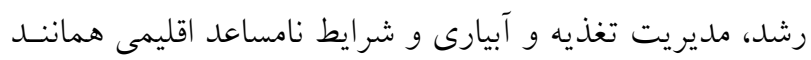

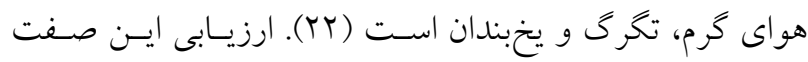

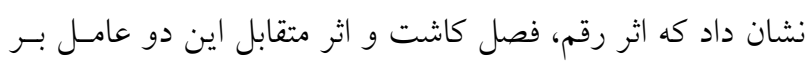

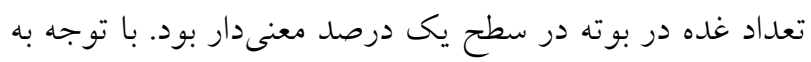

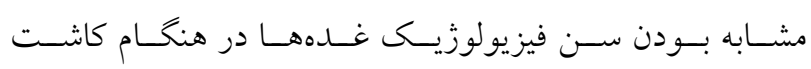

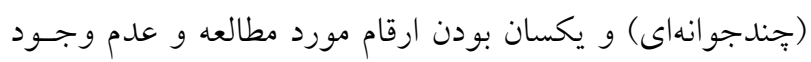
اختلاف معنسى دار تعـداد سـاقه در دو فصـل كاشــت، مسىتـوان

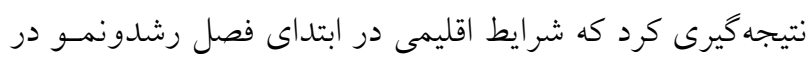

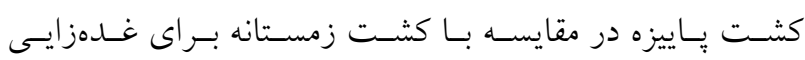

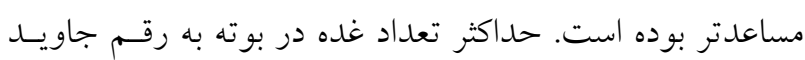
تعلق داشت. افزايش تعداد غده در رقم مزبور در مقايسـه بـا دو

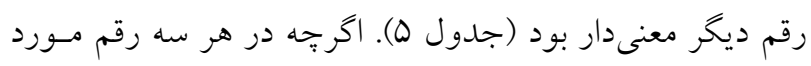

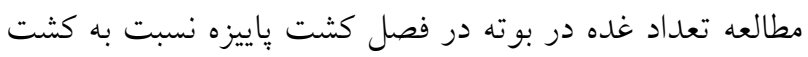

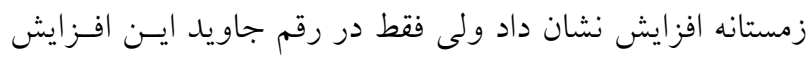

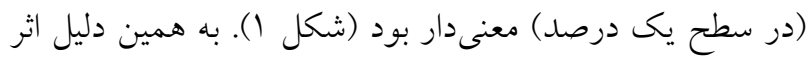

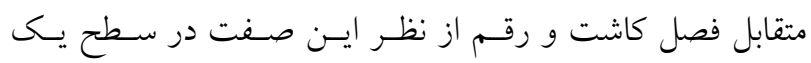
درصد معنى دار شد. تجزيه واريانس دادههاى مربوط به متوسط وزن غـده نشـان داد 


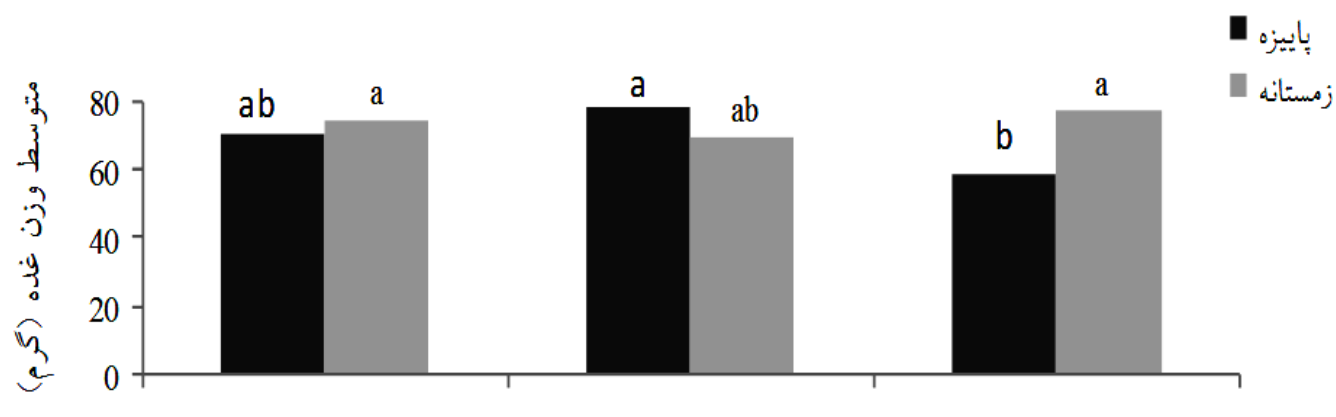

جاويد

رقم

شكل r. مقايسه ميانگين متوسط وزن غده در ارقام مورد مطالعه در دو فصل كاشت باييزه و زمستانه. ميانخين هاى هر ستون كه حداقل در

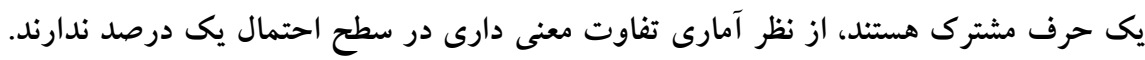

\section{نتيجه گيرى}

نتايج اين يزوهش مشخص كرد كـه در كشـت بـاييزه مـــت زمـان مرحله رشد جوانهها از كشت زمستانه كوتاهتر ولـى مرحلـه حجـيم شدن غلدها طولانى تر بود. مدت زمان رشـــ ســزينهاى در هـر دو فصل كاشت برابر بود. در جه روز رشد دريافت شده، واحسـ هليـو ترمال و شاخص نـورى دمـايى در كشـت يـاييزه در مرحلـه رشـد جوانهها از كشت زمستانه بيشتر ولى در مرحله حجيم شدن غدههـا كمتر بود. بالا بودن دمـا در دوره حجـيم شــدن غـدههـا در كشـت

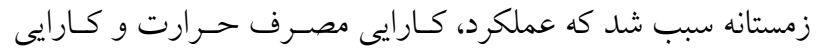
مصرف واحد هليو ترمال در اين فصل كاشت در مقايسه بـا كشـت باييزه كاهش معنى دارى را در سطح يك درصد نشان دهد.

$$
\begin{aligned}
& \text { كشت باييزه نسبت به كشت زمستانه بهترتيـب Q } \\
& \text { درصد بيشتر بود (جدول ه). علت اين موضوع بالا بودن دما در } \\
& \text { دوره حجيم شدن غده (و بهخصوص از اواسـط ارديبهشـتمـاه } \\
& \text { به بعد) مىتواند باشد كه منجر به دريافت واحد حرارتى اضافى } \\
& \text { و غير مؤثرى در اين فصل كاشت شده است. يايين بودن كارايى } \\
& \text { مصرف حرارت بهدليل بالا بودن دمـا در مرحلـه حجـيم شـدن } \\
& \text { غدهها توسط ورتينختـون و هـاتجــين سـون (ها) و مـاجى و } \\
& \text { همكاران (19) نيز كزارش شده است. بيشترين كـارايى مصـرف } \\
& \text { حرارت و مصرف واحد هليوترمال به رقم جاويد تعلق داشت و } \\
& \text { از نظر اين دو شاخص رقم جاويد بـر دو رقـم ديخـر در سـطح } \\
& \text { يك درصد برترى داشت (جدول ه). }
\end{aligned}
$$

منابع مورد استفاده

1. Agricultural, Food and Rural Development Department . 2005. Botany of the potato plant. Avaiable on line at http://www1 agric.gov.ab.ca.\$department/deptdosc.nsf/all//opp9547.

2. Amrawat, T., N. S. Solanki, S. K. Sharma, D. K. Jajoria and M. L. Dotaniya. 2013. Phenology growth and yield of wheat relation to agro-meteorological indices under different sowing date. African Journal of Agricultural Research 8(49): 6366-6374.

3. Anonymus. 2016. Agricultural statistics, first volume-horticultural and field crop, 2014-15. Ministry of Jihad-eAgriculture, Programing and Economic Deputy, Statistics and Information Technology Office. Tehran. PP: 88. (In Farsi).

4. Birch, P. R., G. Bryan, B. Fenton. E. M. Gilroy, I. Hein, J. T. Jones, A. Prashar, M. A. Taylor, L. Torrance and I. K. Toth. 2012. Crops that feed the world 8: Potato: are the trends of increased global production sustainable? Food Security 4(4): 477-508.

5. Brown, P. H. 2007. The canon of potato science: 37 . stolonization, tuber induction and tuberization. Potato Research 
50: $363-365$.

6. Darabi, A. 2007. Effects of planting density and harvesting date on yield and yield components of some potato cultivars in Behbahan. Seed and Plant 23(2): 233-244. (In Farsi).

7. Darabi, A. and S. A. Eftekhari. 2014. Investigation the phenology stages and some growth indices of three potato (Solanum tuberosum L.) cultivars. The plant production Agronomy, Breeding and Horticulture (Scientific Journal of Agriculture) 37(2): 51-67. (In Farsi).

8. Ewing, E. E. and P. C. Struik. 1992. Tuber formation in potato: induction, initiation and growth. Horticultural Reviews 14: 89 -98.

9. Friedman, M. 1997. Chemistry, biochemistry and dietary role of potato polyphenols. A review. Journal of Agricultural and Food Chemistry 45(5): 1523-1540.

10. Grijesh, G. K., A. S. Kumara Swamy, S. Sridhara, M. Dinish Kumar, T. S. Vageesh and S. P. Nataraju. 2011. Heat use efficiency and helio thermal units of maize genotypes as influenced by date of sowing under Southern transitional zone of Karanatak state. International Journal of Science and Nature 2(3): 529-533.

11. Hassanpanah, D., A. A. Hossienzaded and N. Allahyari. 2009. Evaluation of planting date effect on Savalan and Agria potato cultivars in Ardabil region. Journal of Food Agriculture and Environment 27(3 and 4): 525- 528.

12. Jones, J. W., G. Hogenboom, C. H. Porter, K. J. Bootee, W. D. Batchlore, L. A. Haunt, P. W. Wilkens, U. Singh, A. Gijman and J. T. Ritchie. 2003. The DSSAT cropping system model. European Journal of Agronomy 18: 235-265.

13. Kazemi, M., H. Hassanabadi and H. Tavakoli. 2011. Potato Production Management. Nashr-e-Amozesh and Tarvij Keshavarzi. Tehran. (In Farsi).

14. KleinKopf, G. E., T. L. Brandt and N. Olsen. 2003. Physiology of tuber bulking. In: Proceeding of the Idaho Potato Conference. USA.

15. Kolasa, K. 1993. The potato and human nutrition. American Potato Journal 70(5): 375-384.

16. Kooman, P. L. and A. J. Haverkort. 1995. Modeling development and growth of the potato crop influenced by temperature and day length. pp. 41-59. In: Haverkort, A. J. and D. K. L. MacKerron (Eds.), Potato Ecology and Modeling of Crop under Conditions Limiting Growth, Kluwer Academic Publishers, Dordrecht.

17. Kumar, N., S. Kumar, A. S. Main and S. Royo. 2014. Thermal indices to crop phenology of wheat (Triticumae stivum L.) and urd (Vignamungo Hepper L.) at Taria region of Uttarkhand. Mausam 65(2): 215-218.

18. Lambert, E. D. S., C. A. B. P. Pinoto and C. B. D. Meneze. 2006. Potato improvement for tropical conditions: I. Analysis of stability. Crop Breeding and Applied Biotechnology 6: 129-135.

19. Maji, S., M. Bhowmick, P. Chakraborty, S. Jena, S. K. Dutta, R. Nath, P. Bandyopahyay and P. K. Chakraborty. 2014. Impact of Agro-meteorological on growth and productivity of potato (Solanum tuberosum L.) in Eastern India. Journal of Crop and Weed 10(2): 193-189.

20. Malakouti, M. J. and M. M. Tehrani. 1999. The role of micronutrients in increasing yield and quality of agricultural crops. Tarbiat Modarres University Publication. Tehran. (In Farsi).

21. Midmore, D. J. 1992. Potato production in the he tropics. pp. 728 - 793. In: P. M. Harris (Ed.), Potato Crop. Chapman and Hall, London.

22. Mihovilovich, E., C. Carli, F. de Mendiburu, V. Hualla and M. Bonierbale. 2009. Protocol tuber bulking maturity assessment of elite and advanced potato clones. International Potato Center. Lima.

23. Moorby, J. and F. L. Milthorpe. 1975. Potato. pp. 225-257. In: L.T. Evans. (Ed.), Crop Physiology: Some Case Histories. Cambridge University Press, London.

24. Mote, B. M., M. Kumar and Y. C. Ban. 2015. Agro-meteorological indices of rice cultivars under different environmental at Navsari (Gujrat), India. Plant Archives 15(2): 913-917.

25. O'brien, P. J., E. J. Allen and D. M. Firman. 1998. A review of some studies into tuber initiation in potato (Solanum tuberosum L.) crops. Journal of Agricultural Science, Cambridge 130: 251- 270.

26. Mousapour Gorji, A. and H. Hassanabadi. 2012. Analysis of growth and variation in trends of potato $c v$. Agria in different planting date. Seed and Plant Production Journal 28-2 (2): 187-208 (In Farsi).

27. Parvizi, K., J. Souri and R. Mahmoodi. 2011. Evaluation of cultivation date on yield and amount of tuber disorders of potato cultivars in Hamadan province. Journal of Horticultural Science 25(1): 82-93. (In Farsi)

28. Rezaee, A. and A. Soltani. 1996. Introduction to Potato Production. Jehad-e-Daneshgahi Mashhad Publication, Mashhad. (In Farsi).

29. Rao, V. U. M., D. Singh and R. Singh. 1999. Heat use efficiency of winter crop in Haryana. Journal of AgroMeteorology 1(2): 143-148.

30. Ratnam, M. and S. Rajamani. 2016. Heat use thermal and radiation use efficiency of Bt. cotton as influenced by sowing windows under rainfed conditions of Andhra Pradesh. International Journal of Applied and Pure Science and Agriculture 261-263.

31. Singh, M. P., K. R. Lallu and N. B. Sign. 2014. Thermal requirement of Indian mustard (Brassica juncea) at different phonological stages under late sown condition. Indian Journal of Plant Physiology 19(3): 238-243. 
32. Sreeniavas, G., M. Devender Redady and D. Raji Redady. 2010. Agro-meteorological indices in relation to phenology of aerobic rice. Journal of Agrometeorological 12(2): 241-244.

33. Tibbitts, T. W., W. Cao and S. M. Bennett. 1992. Utilization of potato plant for life support in space. V. Evaluation of cultivars in response to continuse light and high temperature. Amrican Potato Journa 69: 229-237.

34. Waglay, A., S. Karboune and I. Alli .2014. Potato protein isolates: recovery and characterization of their properties. Food Chemistry 142: 373-382.

35. Worthington, C. M. and C. M. Hutchinson. 2005. Accumulated growing degree days as a model to determine key developmental stages and evaluate yield and quality of potato in Northeast Florida. Proceedings of the Florida State Horticultural Society 118: 98-101. 


\title{
The Investigation of Planting Season Effect on Yield and Phenology of Potato (Solanum tuberosum L.) Culivars Using Thermal Indices
}

\author{
A. Darabi ${ }^{*}$ \\ (Received: November 27-2017; Accepted: May 5-2018)
}

\begin{abstract}
In order to evaluate the effect of autumn and winter planting on yield and phenology of potato cultivars using thermal indices an experiment was coducted in split plot in time based on a radomized compelet block design with three replications at Behbahan Agriculture Research Station in Khuzestan province, south of Iran in 2014 and 2015. Cultivar (Sante, Savalan and Javid) was considered as main plot and planting season (autumn and winter planting) as sub plot. In Autumn and winter planting seasons tubers were planted in early October and early December, respectively. Tubers were harvested in early March and mid May in autumn and winter planting seasons, respectively. The duration of sprout dvelopement in the autumn planting season was 14 days shorter than winter planting season, but tuber bulking duration was 25 days longer in the latter planting season. Futhermore, growing degree days, helio thermal unit and photo thermal index of sprout development stage in autumn planting season $\left(117.41^{\circ} \mathrm{C}\right.$ day, $1967^{\circ} \mathrm{C}$ day hour and $9.29^{\circ} \mathrm{C} \mathrm{day} \mathrm{day}{ }^{-1}$, respectively) were greater than winter planting. However these agro-meteorologial indices at tuber bulking stage $\left(537.58^{\circ} \mathrm{C}\right.$ day, $4168.79^{\circ} \mathrm{C}$ day hour and $10.42^{\circ} \mathrm{C}$ day day ${ }^{-1}$, respectively) were smaller in winter planting. Yield, thermal use efficiency and helio thermal use efficiency were reduced (18.36, 34.95 and $31.58 \%$, respectively) due to high temperatures encountered during tuber bulking stage in winter planting as compared with the autumn planting season. The highst yeild, thermal use efficiency and helio thermal use efficiency in both of planting seasons belonged to Javid cultivar.
\end{abstract}

Keywords: Growth degree day, Helio thermal unit, Photo thermal unit, Tuber initiation`

1. Assistant Professor, Seed and Plant Research Improvement Department, Khuzestan Agricultural and Natural Resources Research and Education Center, AREEO, Ahwaz, Iran.

*: Corresponding Author, Email: darabi6872@yahoo.com 